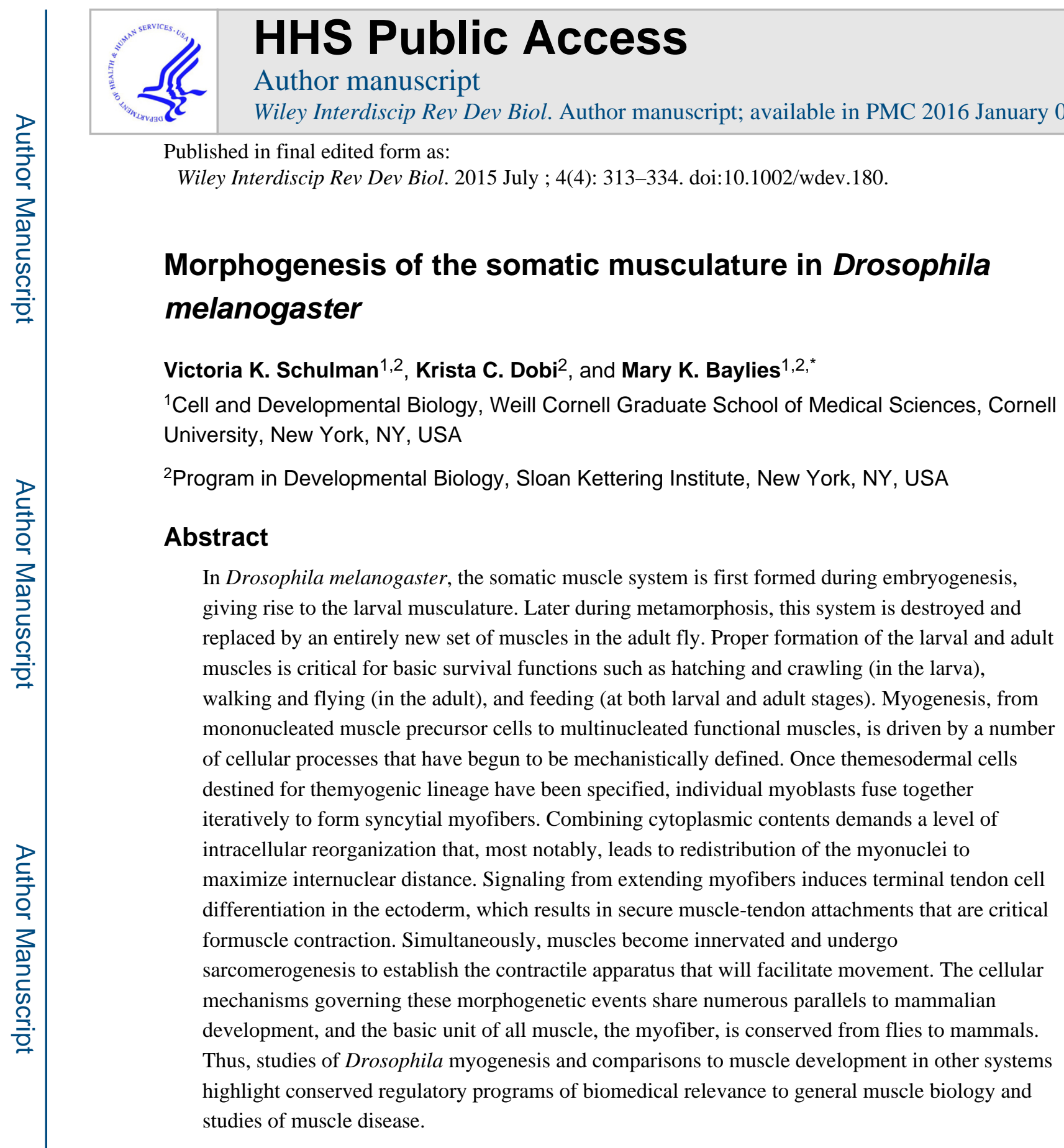

\title{
INTRODUCTION
}

Proper formation of the somatic muscles in Drosophila melanogaster is necessary for many basic survival functions. Embryonic myogenesis builds the larval musculature, which consists of a repeated pattern of hemisegments along the body wall, each of which is composed of 30 unique muscles specified by distinct sizes, shapes, locations, and orientations (Figure 1). ${ }^{1}$ Specification of the myogenic lineage, a process that transforms the

\footnotetext{
(C) 2015Wiley Periodicals, Inc.

*Correspondence to: m-baylies@ski.mskcc.org.

Conflict of interest: The authors have declared no conflicts of interest for this article.
} 
somatic mesoderm into 30 distinctly different muscles, is discussed in detail in the accompanying review. ${ }^{2}$ Despite their defining characteristics, all developing myofibers are multinucleated syncytia that engage similar cellular mechanisms to become functional muscles. Once the body wall muscle cells have been specified (by embryonic stages 11$12),{ }^{2}$ cell-cell fusion occurs between myoblasts to increase muscle mass. The additional nuclei acquired during fusion then move apart from one another, positioning themselves with regular spacing throughout the length of the developing myotube. Extending myotubes must also make contact with tendon cells in the epidermis to form stable muscle attachments that can withstand muscle contraction. Finally, innervation and formation of the sarcomeres, the individual contractile units of muscle, are necessary to allow transmission of neural inputs that translate into movement. Collectively, these cellular processes lead to the formation of mature myofibers that support muscle function. Moreover, the cellular events that drive morphogenesis are conserved from flies to mammals, establishing Drosophila as a highly useful model organism to study general muscle biology and disease.

In Drosophila, myogenesis occurs throughout embryogenesis, culminating at stage 17 with mature myofibers that begin to contract. ${ }^{1,3}$ Muscle contraction facilitates hatching, larval movement, and feeding. Larvae progress through three larval stages of development, known as instars, spanning 5 days during which the muscles increase in size as the organism grows approximately $80-100$ fold. ${ }^{4}$ Maintenance of muscle integrity during this growth is essential, as muscle function is also required for pupariation. ${ }^{5}$

During pupal development, the majority of the larval muscle system is destroyed by histolysis and subsequently rebuilt into the adult musculature. Although less is known about adult myogenesis, adult muscle formation follows a similar series of cellular events as observed in the embryo: myoblast fusion, organelle positioning, tendon attachment, innervation, and sarcomere formation. These processes are completed by the end of metamorphosis, resulting in an adult musculature that supports eclosion from a pupal casing and many other adult fly activities such as walking, flying, jumping, feeding, and mating.

In its most basic sense, morphogenesis is the process of change. In muscle, this requires the differentiation of a small, round, mononucleated cell into a larger, multinucleated cell with a defined shape and complex internal architecture. While each step of this transition is regulated by specific molecules and signaling pathways, a common element shared by the different cellular processes governing muscle morphogenesis is the use of the cytoskeleton. In both the embryo and the adult, cytoskeletal remodeling drives cell fusion, moves and maintains organelles in their positions, mediates attachment to other tissues, and builds interlaced structures that facilitate contraction. Throughout this review, as we highlight the different genes and proteins required for each step of myogenesis, we will also address how actin filaments and microtubules contribute to numerous aspects of morphogenesis. What follows is a comprehensive summary of the most updated cellular models, which have evolved significantly since the first discovery of these critical processes and could continue to change as future studies shed light on various aspects of these models that remain unclear. 


\section{MYOBLAST FUSION}

Muscle is one of the few multinucleated tissues generated by cell-cell fusion. Many transcriptional networks and signaling cascades direct the specification of two distinct sets of mononucleated myoblasts required for embryonic muscle development: (1) founder cells (FCs), which contain all of the transcriptional information necessary to generate a specific muscle, and (2) fusion-competent myoblasts (FCMs), a relatively naïve population of cells that contribute to muscle mass. ${ }^{1,6}$ Once FCs and FCMs are properly specified, ${ }^{2}$ fusion occurs between these two populations of myoblasts to form multinucleated myofibers. Since there have been several excellent, recent reviews on myoblast fusion, ${ }^{7-9}$ we provide a summary of the process and include recently published data.

Myoblast fusion in Drosophila is heterotypic and directional. ${ }^{1,6}$ Fusion only occurs between FCs and FCMs, never between like-cells. Additionally, FCMs protrude into FCs/growing myotubes via invasive podosome-like structures to facilitate a fusion event. ${ }^{10,11}$ Upon fusing, the nucleus of the FCM adopts the transcriptional profile of the FC. ${ }^{6}$ Depending on the particular muscle it seeds, each FC will incorporate a predetermined number of FCMs. In the final pattern, certain muscles stereotypically contain as few as three nuclei (indicative of two fusion events), whereas others consistently incorporate up to 25 nuclei (24 fusion events). ${ }^{1,4,12}$ However, multiple fusion events to the same myotube do not occur simultaneously. ${ }^{13}$ Fusion is an iterative process, occurring over a 5.5-h period (during embryonic stages 12-15), requiring FCs/growing myotubes to continually reset the cellular programs governing fusion until myofibers with the appropriate number of nuclei are achieved.

Myoblast fusion occurs in five broad steps: (1) recognition and adhesion between an FC (or a growing myotube) and an FCM (Figure 2(a)), (2) cytoskeletal rearrangement at the site of fusion (Figures 2(b) and 3), (3) pore formation in the fusing cell membranes (Figure 2(b)), (4) mixing of cytoplasmic contents and nuclear reprogramming (Figure 2(c) and (d)), and (5) resetting of the cellular machinery to facilitate additional fusion events (Figure 2(e)). This iterative process is tightly controlled by a number of proteins necessary for each step.

\section{Recognition and Adhesion}

Recognition and adhesion are mediated by cell type-specific immunoglobin (Ig) domaincontaining transmembrane proteins. FCs express both Dumbfounded (Duf, also known as Kin-of-Irre C, or Kirre), which is exclusive to FCs, ${ }^{14}$ and Roughest (Rst, also known as Irregular chiasm C, or Irre C), which is expressed by both FCs and FCMs. ${ }^{15}$ Loss of Duf or Rst in the FC has a minimal effect on fusion, whereas simultaneous loss of both proteins completely blocks fusion. ${ }^{14,15}$ Thus, Duf and Rst have overlapping functions. Conversely, FCMs express Sticks-n-stones (Sns) and Hibris (Hbs). ${ }^{16-18}$ Although Sns and Hbs share overlapping functions, overexpression of $\mathrm{Hbs}$ cannot completely compensate for the loss of Sns, suggesting that Sns serves the dominant role during recognition and adhesion. ${ }^{18}$ All four proteins (Duf, Rst, Sns, and Hbs) have large extracellular domains that mediate adhesion between the two cell types (Figure 3, blue). Moreover, interactions between these cell type-specific proteins ensure that only heterotypic fusion events occur. 


\section{Cytoskeletal Remodeling at the Site of Fusion}

Following recognition and adhesion, there is a membrane enrichment of the phosphoinositide, $\mathrm{PI}(4,5) \mathrm{P} 2$ (commonly known as $\mathrm{PIP}_{2}$ ), at the contact site of both the FC and FCM. ${ }^{19}$ This enrichment facilitates intracellular signaling events mediated by the Ig domain-containing proteins (Figure 3, blue) and their adaptors (Figure 3, orange) that lead to local changes in the actin cytoskeleton. ${ }^{20-23}$

In the FC, activation of Duf recruits the multi-domain adaptor proteins, Dreadlock (Dock) ${ }^{23}$ and Rolling Pebbles (Rols, also known as Antisocial, or Ants), ${ }^{20-22}$ to the cell membrane. Rols can interact with the guanine nucleotide exchange factor (GEF), Myoblast City (Mbc), in recruiting the small GTPase, Rac, to the site of fusion in a PI(4,5)P2-dependent manner. ${ }^{11,19,22,24,25}$ Moreover, a second GEF, Loner, is also responsible for the localization of Rac in FCs. ${ }^{26}$ Rac and Kette subsequently activate SCAR/WAVE, a Wiskott-Aldrich Syndrome protein (WASp) family member, that serves as an actin nucleation-promoting factor to induce Arp2/3-based branched actin polymerization. ${ }^{27-29}$ Simultaneously, Rols recruits D-Titin in a Duf-dependent manner to the fusion site. ${ }^{20}$ Although the role of D-Titin at this location is not well understood, previous work demonstrated that D-Titin is required for myoblast fusion and proposed that D-Titin contributes to actin-based cytoskeletal rearrangements in the FC. ${ }^{30}$

Changes in the actin cytoskeleton also occur in the FCM. The intracellular domain of Sns binds to Dock and DCrk, which recruit two FCM-specific proteins, Solitary (Sltr, also

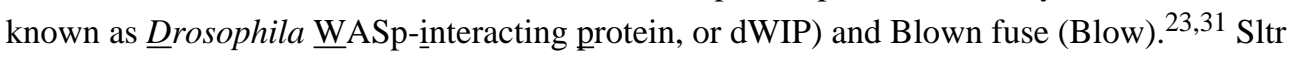
and Blow compete for WASp binding, controlling its stability. WASp activity, in turn, regulates Arp2/3-based actin polymerization at the site of fusion. ${ }^{28,31,32}$ Additionally, Crk can physically interact with Mbc. ${ }^{25,33}$ Although this interaction has been shown to be dispensable for Mbc activity, ${ }^{33}$ Mbc-influenced recruitment and activation of Rac aids in localizing WASp and SCAR/WAVE to the PI $(4,5) \mathrm{P} 2$-enriched contact site in the FCM, ${ }^{19,25,34,35}$ which further influences branched actin polymerization via the Arp2/3 complex (Figure 3). Moreover, recent data establish additional components required for actin organization at the fusion site: two Drosophila Type I p21-activated kinases, DPak3 and DPak1, function downstream of Rac activity and are required for the organization of branched actin into stiff bundles required for fusion progression. ${ }^{11}$ The targets of the DPaks and how these regulate actin organization remain for future investigation.

Collectively, activities in both the FC and the FCM converge at the fusion site, generating a dense region of actin polymerization. ${ }^{27}$ Although both cell types actively polymerize actin, higher magnification studies demonstrated that the dense core of actin, known as the actin focus,${ }^{27}$ predominantly resides within the FCM, while a thin actin sheath in the FC apposes this focus ${ }^{10,25}$ (Figure 3, red). It remains unknown how similar signaling activities in both the FC and the FCM lead to very different organizations of actin in each fusing partner. It is likely that cell type-specific proteins regulate actin dynamics to form each distinct structure. These additional components of myoblast fusion await identification. 


\section{Pore Formation}

The FCM-derived actin focus forms the foundation of the invasive podosome-like structures that facilitate fusion. Actin filaments within the focus begin to extend and protrude into the FC/myotube, deforming the cell membrane.${ }^{10}$ Blow, Rac, and DPak activity promote the invasive nature of these actin-based protrusions, which is thought to induce pore formation in the membranes. ${ }^{10,11,25,32}$ How actin polymerization alone provides the force necessary for these invasive structures to protrude into the $\mathrm{FC} /$ growing myotube remains to be investigated. Likewise, the role of the FC-specific actin sheath in gating membrane fusion is unclear.

One possibility that should be entertained in future work is that the invasive podosome model may be an elaborate extension of an earlier model of fusion proposed decades ago. Based on electron microscopy, previous work initially suggested that numerous smaller pores formed in the membranes at the site of fusion. ${ }^{36}$ Subsequent membrane breakdown between pores was thought to create a single continuous membrane around both fusing partners. ${ }^{36}$ Although this earlier model differs from the more recent invasive podosome model, the two are not mutually exclusive. It is possible that a series of distinct smaller pores are formed first, which become joined to form a single pore as the invasive actinbased structures extend into the adjacent cell. Thus, the force supplied by actin polymerization during podosome extension may only be sufficient at driving pore formation after a few small holes in the membranes are present. Despite the evidence supporting each individual model, additional work is needed to reconcile the uncertainties of how pore formation occurs, as the two proposed mechanisms might be more interdependent than previously thought. Moreover, it is unclear whether either model of fusion sufficiently explains myogenesis.

Nevertheless, once a fusion pore is formed, recent work suggests that continued SCAR/ WAVE and WASp activity alters the actin cytoskeleton once again to expand the width of the pore. ${ }^{35}$ Subsequent dissolution of the actin focus is believed to be the last phase of actin remodeling necessary to promote fusion, but how this final step of actin remodeling occurs remains unknown.

\section{Cytoplasmic Mixing and Nuclear Reprogramming}

Upon pore formation and dissolution of the actin focus, cytoplasmic-labeling experiments demonstrate that the cytoplasm becomes contiguous between the two cells. ${ }^{10}$ Furthermore, the newly introduced nucleus of the FCM gradually adopts the transcriptional fate of the FC/ myotube, as visualized by either in situ hybridization or fluorescently tagged nuclear proteins expressed under the control of FC-specific muscle identity gene promoters. ${ }^{27,37-39}$ Relatively little is known about how this nuclear reprogramming occurs. Moreover, whether a subset of genes becomes expressed or if the entire transcriptional program of the newly incorporated nucleus changes remains to be determined.

\section{Resetting the Fusion Machinery}

The growing myotube prepares for another round of fusion by resetting the proteins necessary to mediate interactions with another FCM. This is accomplished, in part, by Rols 
activity. In addition to stimulating actin rearrangements in the FC, Rols is also necessary to return Duf to the cell membrane for additional rounds of fusion. ${ }^{40}$ However, when Rols is absent, more than one fusion event is able to occur in a single muscle. ${ }^{21,22}$ These observations may suggest that there is initially sufficient Duf at the cell membrane to promote 1-2 fusion events, but because Rols is not present to recycle Duf to the cell surface, subsequent fusion events cannot occur. Alternatively, these data may suggest that additional proteins are required for this process that have not yet been identified.

Another aspect of fusion that remains unclear is how myotubes reset the fusion machinery the correct number of times. While a universal counting mechanism could govern myoblast fusion, that mechanism would not account for differences in nuclear number observed between myofibers. Each mature myofiber consistently contains a reproducible number of nuclei that differs from other myofiber subtypes; some myofibers contain as few as three nuclei, while others contain as many as $25 .^{1}$ These observations indicate that a predetermined number of fusion events occurs for a given myofiber, but, to date, no counting mechanisms have been identified. Additionally, since this information is likely entrained by muscle FCs, it is possible that counting mechanisms may be unique to a given myofiber. Lastly, recent evidence indicates that a switch to glycolysis is a potent driver of fusion. ${ }^{41}$ How this metabolic switch interfaces with the known fusion machinery and affects counting mechanisms remains an important open question.

\section{ORGANELLE POSITIONING: FOCUS ON NUCLEAR POSITIONING}

Following myoblast fusion, each myotube contains multiple nuclei, ranging between 3 and 25 , depending on myofiber identity. ${ }^{1}$ These nuclei do not simply aggregate, as recent work demonstrates that these nuclei must adopt specific final distributions within each myofiber for the muscles to function properly. ${ }^{12,42-45}$ Prior to this work, it was thought that the nuclei became evenly distributed within each muscle through passive actions, owing to the shared cytoplasm of each syncytial cell and contractile forces that inherently redistribute cytoplasmic contents. However, the deliberate and precise process of nuclear positioning is now recognized as a critical step of myogenesis that is required for muscle function.

Although nuclear disorganization is observed in all muscles when certain proteins are lost, ${ }^{12,43}$ the steps of myonuclear positioning have been best characterized in the lateral transverse (LT) muscles of the developing embryo. ${ }^{12,42,44,45}$ Nuclear labeling experiments highlighted that LT myonuclei undergo a stereotypic series of movements throughout embryonic development. ${ }^{12}$ Post-fusion, the myonuclei are located in a single group within the myotube. Over the course of development, these nuclei segregate into smaller groups that follow characteristic migration patterns before evenly distributing throughout the myofiber at the end of embryonic stage $17 .{ }^{12}$

\section{Motor Proteins and Microtubule-dependent Processes}

Myonuclear movements have been found to be dependent upon the microtubule cytoskeleton. Both the plus- and minus-end directed microtubule motor proteins, Kinesin and Dynein, respectively, as well as several motor protein regulators are necessary to position myonuclei. ${ }^{12,42,44,45}$ One of the first studies of myonuclear movement showed that 
loss of the microtubule-associated protein, Ensconsin (Ens), leads to a single cluster of myonuclei that persists throughout development. ${ }^{12}$ Ens and its mammalian counterpart, MAP7, were identified as necessary linkers between the microtubule cytoskeleton and the stalk region of Kinesin. ${ }^{12}$ This work proposed that Ens enables Kinesin to crosslink microtubules. By securely binding its cargo domain to one microtubule and processing its motor domain along the other, Kinesin effectively slides two microtubules past one another, which increases the distance between the nuclei bound to those microtubules ${ }^{12}$ (Figure 4(a), gray and pink).

Kinesin also works in cooperation with Dynein to position myonuclei via two distinct mechanisms separated by intracellular location: (1) at the nuclear surface, and (2) at the cell cortex. In the first mechanism, Kinesin exerts a pulling force on the front of a moving nucleus, while Dynein activity toward the rear of the nucleus is necessary to complete a translocation step and facilitate forward motion. ${ }^{45}$ These activities deform the shape of the nucleus (Figure 4(a), white teardrop), likely allowing myonuclei to navigate around obstacles in dense cellular environments, as observed in other systems. ${ }^{46}$

In the second mechanism, Kinesin is required to relocate Dynein from the nuclear periphery to the cell cortex. ${ }^{42,44}$ There, cortically anchored Dynein generates pulling forces on microtubules that move myonuclei into place, ${ }^{42}$ analogous to the mechanisms of spindle positioning observed in budding yeast ${ }^{47}$ (Figure 4(a), far right). Multinucleated myofibers uniquely exhibit pericentriolar material around the entire periphery of the nuclei. ${ }^{48}$ This results in a radial array of microtubules in which the minus-ends originate at the nuclear periphery, while the plus-ends extend outward toward the cell membrane. ${ }^{45}$ This facilitates Kinesin-dependent localization of Dynein to the cell cortex ${ }^{42,44}$ similar to the manner in which Kinesin targets Dynein to microtubule plus-ends in other contexts. ${ }^{49,50}$

\section{Regulation of Motor Proteins}

The precise coordination of Kinesin and Dynein activities requires a host of motor protein adaptors, including Kinesin light chain (Klc), Dynein light chain (Dlc), p ${ }^{150} /$ Glued, Inscuteable (Ins), Rapsynoid (Raps, or Partner of inscuteable (Pins) in mammals), cytoplasmic linker protein-190 (CLIP-190, or CLIP-170 in mammals), and Sunday Driver (Syd, or JNK-interacting protein 3 (JIP3) in mammals). ${ }^{42,44,45}$ Specifically, Klc and Glued are respectively required to mediate Kinesin and Dynein as they deform the nucleus to promote forward movement. ${ }^{45}$ Analogous to Pins function in other contexts, ${ }^{51}$ Raps is required to anchor Dynein to the cell cortex to facilitate Dynein-mediated pulling of myonuclei into final position ${ }^{42}$ (Figure 4(a), purple). CLIP-190 aids in microtubule searchand-capture mechanisms ${ }^{52}$ to promote and maintain the integrity of the microtubule cytoskeleton upon which these motors act ${ }^{42,53}$ (Figure 4(a), orange), and other regulators support general motor function. $42,46,54,55$ Additionally, there are likely many more proteins that influence motor protein function in this context that have yet to be identified.

The most interesting finding, however, was that Syd (JIP3) influences motor activity in response to induction of the JNK signaling pathway. ${ }^{44}$ While this characteristic of JIP family proteins has been well documented, ${ }^{56,57}$ this finding was the first identification that the process of myonuclear positioning is regulated in a JNK signaling-dependent manner.

Wiley Interdiscip Rev Dev Biol. Author manuscript; available in PMC 2016 January 01. 
Both loss and over-activation of the JNK signaling pathway leads to similar defects in myonuclear position, owing to the mislocalization of motor proteins (albeit differently) in each scenario. ${ }^{44}$ Specifically, JNK signaling and Syd are required to promote Kinesindependent translocation of Dynein to the cell cortex ${ }^{44}$ (Figure 4(a), red and light blue). Moreover, these findings suggest that Kinesin and Dynein are both initially perinuclear, where the motors are known to impact nuclear shape to promote myonuclear translocation. ${ }^{45}$ How JNK signaling, relayed via Syd, segregates and coordinates the two mechanistically distinct Kinesin- and Dynein-dependent pathways and how JNK signaling is activated in this context are important topics for future research.

\section{KASH and SUN Proteins}

Another set of proteins shown to be important for nuclear positioning in Drosophila muscle are the SUN and KASH transmembrane proteins, Klaroid (Koi) and Klarsicht (Klar), of the inner and outer nuclear membranes, respectively. ${ }^{43}$ SUN proteins are defined by a $\underline{S} a d 1 p-$ UNC-84 (SUN) homology domain ${ }^{58}$ that binds to the characteristic Klarsicht- $\underline{\text { Anc-1-Syne }}$ homology (KASH) domain ${ }^{59}$ of KASH proteins within the perinuclear space of the nuclear envelope. SUN proteins span the inner nuclear membrane, while KASH proteins span the outer nuclear membrane, effectively linking the nucleoskeleton to the cytoskeleton. ${ }^{60,61}$ While the mechanistic details regarding Koi and Klar function in the context of myonuclear positioning remain unclear, SUN and KASH domain-containing proteins have been shown to interact with motor proteins. ${ }^{62}$ Thus, it is speculated that Koi and Klar may be involved in motor-dependent nuclear positioning in muscle tissue despite that a direct connection between SUN, KASH, and motor proteins has yet to be identified in this context (Figure 4(b)).

Interestingly, loss of another KASH protein, MSP-300, specifically impairs myonuclear spacing during larval stages of development without affecting embryonic nuclear positioning. ${ }^{43}$ This observation raised the possibility that, similar to nuclear positioning in the Caenorhabditis elegans hypodermis, ${ }^{59,61,63}$ there may be distinct sets of proteins specifically required for moving nuclei and others for anchoring nuclei in place. In support of this hypothesis, MSP-300 was shown to be important for nuclear anchoring during Drosophila oogenesis, ${ }^{64}$ and similar to its orthologs, ${ }^{59,65}$ MSP-300 contains a calponin homology $(\mathrm{CH})$ domain that facilitates binding to actin filaments. ${ }^{65}$ Thus, once myonuclei reach their final positions, it is thought that MSP-300 securely anchors them in place by tethering them to other cytoskeletal components ${ }^{43}$ (Figure 4(b)).

\section{Myonuclear Positioning and Muscle Function}

Loss of any of the aforementioned proteins leads to decreased muscle function, as evidenced by impaired larval locomotion, ${ }^{12,42-44}$ mimicking muscle disease states in humans. These data highlight the necessity for proper myonuclear positioning, despite that it remains unclear how correct myonuclear spacing translates to efficient muscle function (Box 1). These findings also beg the question of whether mislocalization of other organelles may also contribute to cellular dysfunction. All organelles and cytoplasmic contents must be reorganized following myoblast fusion, and it has been shown that mitochondria fail to evenly distribute throughout the muscle cell when myonuclei are clustered together. ${ }^{12}$ 
However, since the mitochondria are normally found around the nuclear periphery, it is unclear whether these mitochondria are properly positioned (relative to the nuclei) or if they, too, are actively mispositioned in these backgrounds. Conversely, these findings raise the possibly that myonuclei are mispositioned as a result of other organelles being mislocalized. Additional studies are necessary to answer these outstanding questions.

\section{BOX 1}

\section{THE MYODOMAIN HYPOTHESIS}

The biological necessity for proper myonuclear spacing is evidenced by impaired locomotion in larvae with disrupted myonuclear distributions. ${ }^{12,42-44}$ On the cellular level, it is unclear how these defects impact muscle function; however, heterokaryon studies in mammalian cell culture offer one possible explanation. Researchers fused a human fibroblast to a developing mouse myotube and used species-specific antibodies to detect human proteins within the resulting syncytium. ${ }^{66}$ Interestingly, proteins generated by the human nucleus remained near that nucleus despite the shared cytoplasm throughout the cell. ${ }^{66}$ This observation led to the myodomain hypothesis, which postulates that each nucleus is responsible for maintaining the integrity of the tissue within its immediate vicinity. This provided a mechanism by which large multinucleated cells could be regulated by a series of smaller domains. According to this hypothesis, myofibers with improper nuclear spacing would contain regions of muscle lacking the proteins necessary to support muscle cell structure and function. While this hypothesis has never been directly tested in Drosophila, muscles with mislocalized nuclei often exhibit regions devoid of nuclei that are thinner and misshapen, as if they are beginning to atrophy. ${ }^{12,42-44}$ Furthermore, quantitative measurements of muscle width are significantly decreased in myofibers depleted of microtubules, which are critical for proper myonuclear positioning. ${ }^{67}$

\section{TENDON ATTACHMENT}

Developing myofibers must attach to tendon cells in the epidermis and become innervated to mature into functional muscles. Tendon attachment provides definition to the muscle boundaries and is necessary for the transmission of force between the muscles and the larval body. Thus, attachment and innervation must occur prior to embryo hatching, concurrent with myonuclear positioning, to support movement during larval stages of development.

\section{Early Tendon Cell Specification}

Tendon cells are first specified in the epidermis during stages 11-12, the same developmental time-frame in which muscle FCs are established. ${ }^{68}$ Tendons begin as a field of tendon precursor cells, each with the same differentiation potential. After engaging in myotube-dependent signaling, one cell within this field is selected to terminally differentiate into the tendon cell that will attach to a particular muscle. ${ }^{69,70}$

Specification of tendon precursors is accomplished through Wingless $(\mathrm{Wg})$ and Hedgehog (Hh) signaling in ectodermal cells. ${ }^{68} \mathrm{Wg}$ and Hh promote the expression of StripeB $(\mathrm{SrB})$, 
the longer of the two protein isoforms produced by the stripe gene. ${ }^{71} \mathrm{SrB}$ is an early growth response (Egr)-like transcription factor that is expressed in epidermal cells at the segment border of eachmesodermal hemisegment. ${ }^{68}$ Once activated, SrB positively regulates its own transcription ${ }^{69}$ as well as the transcription of the long isoform of the RNA-binding protein, Held Out Wing $(\operatorname{How}(\mathrm{L})){ }^{72} \mathrm{How}(\mathrm{L})$ degrades stripe mRNA; thus, SrB and How(L) participate in a negative feedback loop to temper the levels of SrB generated through autoregulation. ${ }^{72}$ This maintains $\mathrm{SrB}$ at low levels in all tendon precursors, thereby inhibiting further tendon cell differentiation until signals from an extending myotube are detected (Figure 5(a)).

\section{Terminal Differentiation, Guidance, and Muscle Attachment}

Within the tendon precursors, $\mathrm{SrB}$ also regulates the expression of Slit and Leucine-rich tendon-specific protein (Lrt), which guide extending myofibers to their attachment sites at the segment borders ${ }^{73,74}$ (Figure 5(a) and (b)). Slit is secreted by the tendon precursors, acting as a chemoattractant, and Lrt is a transmembrane protein that mediates final targeting of a myotube to a tendon precursor. Both Slit and Lrt physically interact with Roundabout (Robo), a transmembrane protein that is expressed by the myotube ${ }^{73,74}$ (Figure 5(a) and (b)).

Robo receptors respond to Slit by stimulating the myotubes to secrete Vein, a neuregulinlike ligand for the epidermal growth factor (EGF) signaling pathway ${ }^{75}$ (Figure 5(b)). Vein secretion is regulated by Moleskin (Msk), a nuclear import protein, ${ }^{76}$ and once secreted, Vein binds to Drosophila EGF receptors (DERs) on the tendon precursor that is selected for attachment. This binding activates the Egfr signaling pathway in only that tendon precursor cell and causes neighboring cells to lose the expression of tendon cell markers ${ }^{69,75}$ (Figure 5(b)). DER-mediated Ras signaling upregulates the expression of the short form of How, $\operatorname{How}(\mathrm{S})$, which simultaneously reduces the levels of inhibitory How $(\mathrm{L})$ and stabilizes stripe transcripts. ${ }^{72}$ These functions elevate the expression of both $\mathrm{SrB}$ and the more active isoform of stripe, StripeA (SrA). ${ }^{72,75,77}$ Activation of SrA induces the expression of the tendon-specific proteins, $\beta 1$-tubulin ( $\beta 1$-tub) and Delilah (Dei), facilitating terminal differentiation into a tendon cell and the formation of a secure attachment to an extending myofiber $^{75,77}$ (Figure 5(c)).

\section{Additional Mechanisms of Muscle Attachment}

Additional mechanisms of muscle guidance to tendon cells have been identified for certain muscle subsets. Specifically, the LT muscles are unique, as they do not attach to the segment border (Figure 1) and do not express high levels of Robo. ${ }^{73}$ Ectopic expression of Robo in the LT muscles induces the formation of incorrect attachments at the segment border, ${ }^{73}$ suggesting that the LT muscles target internal tendon cells by a different mechanism. Indeed, the LT muscles express Derailed (Drl), a receptor tyrosine kinase (RTK). ${ }^{78}$ Without Drl, extending LT muscles bypass the available field of SrB-expressing tendon precursors and fail to make the proper myofiber-tendon attachments. ${ }^{78} \mathrm{It}$ is currently unknown how this pathway is specifically activated in the LT muscles or what downstream targets are phosphorylated by Drl. 
The VL muscles also target tendon cells by a unique mechanism. Although the VL muscles attach to the segment border (Figure 1), interactions between Robo, Slit, and Lrt are insufficient to mediate proper attachment. Interactions between the transmembrane protein, Kon-tiki (Kon, also known as Perdido, or Perd), its cytoplasmic partner, Grip (a PDZ domain-containing protein), and the cell-surface protein, Echinoid (Ed), are necessary for targeting the VL muscles to their appropriate attachment sites at the segment borders. ${ }^{79-82}$ Kon expression is not detected in other extending muscles, ${ }^{81}$ suggesting that this mechanism is specific to the VL muscles. To date, it remains unclear why the VL muscles target tendon cells via a different mechanism from other muscles that also attach at the segment border, but these various mechanisms likely contribute to the diversity observed in the final muscle pattern.

\section{Formation of the Myotendinous Junction}

Once the myotubes form preliminary attachments to tendon cells, both cells secrete extracellular matrix (ECM) proteins that promote the formation of the myotendinous junction (MTJ) (Figure 5(d)). Tendon cells deposit Thrombospondin (Tsp) and Laminin (Lam), while the myotubes contribute Tiggrin to the ECM. ${ }^{83-86}$ Tendons also secrete Slowdown (Slow), which prevents premature and incorrect MTJ formation by temporarily sequestering Tsp until its appropriate binding partners are present. ${ }^{87}$ Each cell type then expresses common and unique transmembrane proteins known as Integrins, adhesion molecules that mediate attachment to the ECM. In tendon cells, the Integrin proteins, $a \mathrm{PS} 1$ and $\beta \mathrm{PS}$, are encoded by multiple edematous wings (mew) and myospheroid (mys), respectively. These proteins form an $\alpha \mathrm{PS} 1-\beta \mathrm{PS}$ heterodimer that binds to $\mathrm{Lam}^{70,84}$ (Figure 5(d)). In contrast, the myotube binds to the ECM using the protein products of inflated (inf) and $m y s,{ }^{70}$ which form an $\alpha \mathrm{PS} 2-\beta \mathrm{PS}$ heterodimer that interacts with both Tiggrin ${ }^{85}$ and $\mathrm{Tsp}^{86}$ (Figure 5(d)). Interactions between Integrins and their binding partners are stimulated by intracellular Talin, a FERM domain-containing protein that binds and induces conformational changes in the Integrin molecules in a process known as Integrin activation. ${ }^{88,89}$ Additionally, Zasp (Z-band alternatively spliced PDZ-motif protein), which was first identified as a necessary structural component of the sarcomeres (see Sarcomere Assembly below), is also required for Integrin activation. ${ }^{90}$ Subsequent heterotypic dimerization of Integrin molecules and binding to ECM components establishes the Integrin adhesion complexes (IACs) that effectively crosslink the muscle and the tendon cell.

The intracellular tails of the Integrins are then linked to the cytoskeletons of both the tendon cell and the myotube (Figure 5(d)). Talin directly links Integrins to actin filaments ${ }^{91-93}$ and recruits proteins such as Integrin-linked kinase (ILK), PINCH (also known as Steamer Duck, Stck), and Tensin, ${ }^{94}$ which aid in maintaining secure connections between IACs and the cytoskeleton. ${ }^{94}$ Zasp is also thought to strengthen the interactions between Integrins and the actin cytoskeleton after Talin establishes these initial contacts. ${ }^{95}$

The correct construction of the MTJ is critical for adequate force generation and the maintenance of stable muscle-tendon attachments during muscle contraction. ${ }^{83,93}$ However, during larval growth and development, these attachments are periodically rebuilt to both recycle IACs and form additional IACs as muscles increase in size. MTJ turnover is 
influenced by tensile stress brought on by muscle contraction; ${ }^{96}$ however, the precise mechanisms of MTJ turnover have not yet been clearly elucidated. Despite some uncertainties, evidence suggests that clathrin-mediated endocytosis of IAC components ${ }^{97}$ as well as the activation of Elmo/Rac signaling via nuclear import proteins ${ }^{97,98}$ are necessary to recycle IACs and support continued muscle function during larval growth.

\section{INNERVATION}

Once the MTJ is first established, the muscles become innervated to receive signals from the central nervous system (CNS) and facilitate movement. In Drosophila, the efferent system of motor neurons originates in the ventral nerve cord of the CNS. ${ }^{99}$ Within each hemisegment, groups of axons extend projections out from the CNS in two distinct bundles, known as the segmental nerve (SN) and the intersegmental nerve (ISN). As the $\mathrm{SN}$ and ISN extend dorsally, these nerves branch at stereotypic positions within the hemisegment and smaller bundles of axons will target specific subsets of muscles. ${ }^{100}$ Information encoded by muscle FCs is necessary and sufficient to direct individual axons to specific innervation sites on each muscle. ${ }^{100}$ Once the axon reaches its target muscle, the axonal growth cone develops into a functional synapse between the muscle and the terminal branch of the neuron. ${ }^{99}$

Of the three types of motor neurons in Drosophila, Type-I glutamatergic neurons directly influence their postsynaptic partners and form classical neuromuscular junctions (NMJs) to regulate muscle contraction. ${ }^{101-103}$ Type-I nerve terminals adopt a stereotypic morphology with reproducible branching patterns and terminal-specific numbers of boutons. ${ }^{102-104}$ Boutons are the presynaptic structures that mediate excitatory signal transduction to the muscles. Both bouton size and the total number of boutons at each NMJ are tightly regulated to control the strength of the excitatory signals that are transmitted to the muscles. ${ }^{105}$ Modulating these aspects of bouton organization via continued signaling between the muscle and the nerve terminal ${ }^{106,107}$ becomes particularly important during larval development when significant organismal growth occurs. ${ }^{4,108}$

To respond to signals transmitted via Type-I glutamatergic terminals, muscles locally express glutamate receptors (GluRs) at the postsynaptic membrane. GluRs become activated upon the release of the neurotransmitter, Glutamate, from the presynaptic membrane of the nerve terminal. When activated, the ion channel of the GluR facilitates the influx of $\mathrm{Na}^{2+}$ into the muscle, which leads to $\mathrm{Ca}^{2+}$ release from stores in the muscle, causing the muscle to contract. There are different types of GluRs, distinguished by the identities of the subunits that comprise each receptor. ${ }^{109}$ Distinct GluRs exhibit different activities and localization patterns at the synapse; ${ }^{110}$ thus, they are thought to be involved in modulating signal transmission and synaptic growth. Furthermore, the postsynaptic adaptor protein, Disks Large (Dlg), also impacts the distribution of these GluRs, ${ }^{110}$ providing an additional level of synaptic regulation.

The first coordinated stimulatory muscle contractions are observed at embryonic stage $17 .^{3}$ Prior to stage 17, involuntary uncontrolled muscle twitches can be observed during muscle development. However, these twitches are myogenic in origin, as loss of GluRs only 
disrupts the organized muscle contractions observed during stage $17 .{ }^{3}$ Thus, the developing embryo receives neural inputs following innervation at stage 17 of development. These coordinated contractions result in compressions of individual muscle hemisegments in the dorsoventral body axis as well as accordion-like waves of forwards and backwards movements along the anterior-posterior body axis (peristalsis). These movements facilitate embryo hatching and subsequent larval movement.

\section{SARCOMERE ASSEMBLY}

Concurrent with muscle-tendon attachment and innervation, the myotubes terminally differentiate and build the conserved contractile apparatus that structurally supports muscle contraction from flies to mammals. This is accomplished by constructing a highly ordered array of sarcomeres, individual contractile units of multi-protein complexes concatenated together along the length of the muscle. Sarcomeres are composed of intercalated thick and thin filaments of myosin and actin, respectively, that slide past one another. This sliding action compresses the muscle in the longitudinal direction, thereby generating force and movement (Figure 6(a)).

Across species, sarcomeres in muscle tissue consist of four basic structural components: actin thin filaments, myosin thick filaments, the Z-disk, and the M-line (Figure 6(a)). One sarcomere is defined as the region between two Z-disks. Z-disks are composed of a number of proteins, including $\alpha$-actinin, and Zasp. $\alpha$-Actinin crosslinks actin thin filaments, ${ }^{114}$ and Zasp secures the Z-disk to the membrane via interactions with Integrin adhesion molecules. ${ }^{95}$ Similarly, the M-line crosslinks myosin thick filaments via Myomesin, Obscurin, and Titin. Myomesin and Obscurin are necessary for M-line organization and may aid in linking the M-line to the sarcolemma, the cell membrane of the muscle. ${ }^{115,116} \mathrm{D}$-Titin is a component of both the M-line and the Z-disk that is thought to structurally connect the two to maintain sarcomere organization during contraction by modulating changes in sarcomere length ${ }^{117}$ (Figure 6(a)).

All of the components of the sarcomeres are necessary to respond to signals from the CNS and support muscle contraction. Furthermore, the coordinated development of stable muscle attachments, proper innervations, and functional sarcomeres promotes final muscle maturation. Once these aspects of muscle development are completed, each myofiber constitutes a single muscle in the fully formed embryonic/larval musculature. Subsequently, the embryo hatches into a larva and crawls toward a food source.

During larval stages of development (5 days), a significant amount of organismal growth occurs. Larvae consume 3-5 times their body weight and increase in size by nearly 80-100 fold. ${ }^{4}$ Importantly, the accompanying increase in muscle mass is not due to additional myoblast fusion events, but rather to an increase in myonuclear size as a result of insulin signaling and endoreplication. ${ }^{4}$ As the muscles grow, the length of each sarcomere remains constant, but additional sarcomeres are added to the existing lattices to accommodate changes in muscle length ${ }^{118}$ (Yu and Baylies, unpublished data). Continued sarcomere function and muscle contraction is necessary for larvae to feed, reach a critical mass, and undergo pupariation, which initiates metamorphosis into an adult fly. $4,5,118$ 


\section{ADULT MUSCLE MORPHOGENESIS}

After reaching a critical mass, the larva crawls away from the food source and begins to pupate. Following puparium formation, metamorphosis takes place over 4 days, during which a majority of the larval tissues, including muscle, are histolyzed, and new adult tissues are formed from precursor cells set aside during embryogenesis. Whereas the larval musculature formed during embryogenesis is required for hatching, crawling, larval feeding, and pupariation, ${ }^{5}$ the adult musculature is necessary for activities such as walking, flying, adult feeding, and mating. These distinct sets of somatic muscles are uniquely fine-tuned to fit their functions.

Less is known about adult myogenesis compared to embryonic/larval myogenesis due, in large part, to the difficulties of applying traditional Drosophila genetics to adult settings. For example, mutants with null or severe loss-of-function alleles often result in embryonic lethality, limiting studies during adult development. However, recent work using RNAi expressed in spatially and temporally controlled manners is beginning to overcome these obstacles. ${ }^{119}$ As this work continues, the knowledge gap between embryonic/larval and adult myogenesis narrows, and data show that many of the morphological events that lead to proper muscle formation are shared between these two developmental programs.

Most of what is known about adult myogenesis in Drosophila arises from studies of the muscles in themesothoracic segment. Within the mesothorax, the larger indirect flight muscles (IFMs) elevate the wings and provide most of the power required for flight, ${ }^{120}$ while the smaller direct flight muscles (DFMs) aid in depressing the wings, and the tergal depressor of the trochanter (TDT, or 'jump' muscle) facilitates jumping. ${ }^{2,121}$ The IFMs constitute the majority of the muscle tissue in the mesothorax and are consequently the most well studied adult muscles. Thus, we focus on the adult IFMs for our review of adult muscle morphogenesis. Additional information on other adult muscles can be found elsewhere. ${ }^{122}$

\section{Adult Myoblast Fusion}

The IFMs are composed of two distinct muscle subsets: the dorsal longitudinal muscles (DLMs) (Figure 7(d)) and the dorsoventral muscles (DVMs). These IFM subtypes are established via different mechanisms of myoblast fusion. ${ }^{121}$ Similar to embryonic myogenesis, the DVMs are formed from de novo fusion events between two distinct populations of myoblasts (Figure 2). ${ }^{121}$ During the specification of embryonic muscle FCs earlier in development, asymmetric cell division led to one $\mathrm{FC}$ and one adult muscle precursor (AMP) cell. ${ }^{2}$ AMPs are set aside in a quiescent state until the larval stages of development when they begin to proliferate. AMPs associated with the wing imaginal disks give rise to the adult muscle FCs and FCMs that form the thoracic muscles. ${ }^{124-127}$ Then, as in the embryo, the DVMs are formed via the founder mechanism: fusion between FCs and FCMs (Figure 2). ${ }^{124-127}$

In contrast, the DLMs form by a unique mechanism. During histolysis, three larval muscles in the second mesothoracic hemisegment are spared. These are known as the persistent larval muscles, each of which elongates, splits in two, and serves as a positional template for the proper development of the six DLMs (Figure 7). ${ }^{121}$ Concurrent with fiber splitting, the 
naïve imaginal myoblasts (adult FCMs) fuse with the persistent larval muscles and organize into multiple myofibers. ${ }^{128}$ This highlights an important difference between larval and adult muscles. While larval muscles each consist of a single myofiber, adult muscles are composed of many myofibers, similar to mammalian muscle architecture.

Despite the different organizational properties of the larval and adult muscles, recent work has demonstrated that adult myofiber formation requires many of the same factors required for embryonic myoblast fusion, including Duf, Rst, Sns, WASp, SCAR, Arp2/3, and others ${ }^{129,130}$ (Figure 3). Furthermore, these components are necessary regardless of whether the imaginal myoblasts fuse with adult FCs or persistent muscles. Thus, although some aspects of adult myoblast fusion have not yet been defined due, in part, to functional requirements of certain proteins earlier in development, the cellular mechanisms underlying myoblast fusion are most likely universal.

\section{MTJ Formation and Adult Muscle Attachment}

Formation of the MTJ in adult myogenesis is similar to MTJ formation in the embryo: expression of $\mathrm{Sr}$ in the epidermis determines the site of tendon cell differentiation and muscle attachment, and interactions between common and cell-type-specific Integrin adhesion molecules physically mediate secure attachments between the muscles and tendon cells. ${ }^{131}$

Following puparium formation, $\mathrm{Sr}$ expression is first detected in discrete groups of cells in the wing and leg imaginal disks. ${ }^{131}$ These clusters of Sr-expressing cells give rise to the thoracic cuticle and mediate adult muscle insertions into the epidermis. ${ }^{131,132}$ To make these attachments, filopodial extensions from developing adult myofibers can be observed making contacts at specific positions within these Sr-expressing clusters of cells. ${ }^{133}$ Thus, it is thought that, similar to embryonic myogenesis, myofiber-derived signals likely influence the final differentiation of the tendon cells that ultimately mediate adult muscle attachment (Figure 5(a)-(c)).

As in the embryo, continued $\mathrm{Sr}$ expression induces tendon cells to express $a \mathrm{PS} 1$ and $\beta \mathrm{PS}$ Integrins, while the myofiber expresses $\alpha \mathrm{PS} 2$ and $\beta \mathrm{PS}$ integrins. ${ }^{131}$ Within each cell type, these Integrins form heterodimers that then bind to the heterodimeric Integrin complexes on the opposing cell to mediate final attachment to a myofiber (Figure 5(d)).

Despite that relatively little is known about MTJ formation in adult myogenesis, the identified roles of $\mathrm{Sr}$ and PS Integrins during this process suggest that embryonic and adult muscle attachment proceed via conserved regulatory programs. Interestingly however, viable hypomorphic mutations in $s r$ cause late muscle detachment defects only in the DLMs. ${ }^{134}$ Similarly, a viable allele of mys results in adult flies that lack a properly formed TDT jump muscle. ${ }^{135}$ These findings suggest that, while many features of MTJ formation and muscle attachment are developmentally conserved between embryonic and adult myogenesis, there may be additional muscle type-specific features of adult myogenesis that will be interesting to uncover in future studies. 


\section{Adult Muscle Innervation}

Unlike embryonic myogenesis, in which muscle innervation is one of the final stages of muscle development, innervation in adult myogenesis occurs simultaneously with initial muscle formation. Furthermore, innervation actually influences the final muscle pattern. ${ }^{136-140}$

At the onset of puparium formation, most motor neurons undergo denervation. Additionally, the larval ISN, which remains in contact with the persistent larval muscles, exhibits significant regression of synaptic contacts with its muscle targets. These neurons are then remodeled, adopting more elaborate arborisation patterns to accommodate the new pattern of adult muscles that will form. ${ }^{140}$

Following disk eversion, the imaginal myoblasts associate with motor neurons. ${ }^{121,140}$ Thus, it is thought that, as the motor neurons create new branching patterns toward specific sites in the thorax, they serve as guides to direct myoblasts to the sites of future muscle formation. ${ }^{136}$ Indeed, laser ablation of flight muscle nerves strongly impairs the de novoderived DVMs. ${ }^{140}$ Interestingly, ablation of the same nerves does not affect DLM development, but in the absence of larval scaffolds, the DLMs adopt a DVM fate. ${ }^{140}$ This suggests that maintaining the connection between the persistent larval muscles and the ISN motor neuron is critical for DLM development. Together these data demonstrate that motor neuron arborisation and innervation are a vital for adult muscle patterning.

\section{Sarcomere Formation}

Until recently, very few studies of sarcomerogenesis had been conducted in the adult muscles. However, large-scale RNAi screens have uncovered a number of genes that, when inhibited, give rise to a variety of interesting phenotypes that specifically affect the structure of the sarcomeres in the adult muscles. ${ }^{119}$ Classes of gene products identified by this screen included those with disorganized Z-lines, no M-lines, or no identifiable sarcomeres at all. ${ }^{119}$ The same study further identified mutants with disorganized muscle structure, which may also reflect defects in sarcomere formation.

Capitalizing on the power of Drosophila genetics has also led to the identification of proteins such as Lasp (Nebulin), which serves two distinct roles during sarcomere function to maintain thin filament spacing and attachment to Z-lines. ${ }^{141}$ Other recent work has focused on understanding how tensile stress and mechanical strain contribute to sarcomere arrangement and function in the adult fly. Interestingly, this work demonstrated that Kon, a protein specifically required for VL muscle attachment in the embryo, is necessary for simultaneous IFM attachment and myofibrillogenesis, both of which impact sarcomere function. ${ }^{142}$ These findings highlight the multifunctional roles of Drosophila proteins, suggesting that other proteins with previously identified functions may also be utilized again during adult development.

Additional work has examined the fiber-type differences between the tubular muscles that control movement throughout the head, leg, abdomen, and thorax, and the fibrillar IFMs that control flight. ${ }^{143}$ Tubular muscles contract synchronously, while the IFMs contract asynchronously. Their cellular structures reflect their distinctive contractile needs and 
function. Recent work has identified genes regulating the choice between a tubular or fibrillar morphology. ${ }^{144}$ Further study of these promising candidates will undoubtedly shed light on adult myogenesis and reveal both similarities and differences between larval and adult sarcomerogenesis.

\section{CONCLUSION}

Morphogenesis, the process by which individual cells change and develop into complex tissues, requires careful coordination of numerous proteins, signaling cascades, and cytoskeletal filaments. Elucidating the precise details of the cellular events governing morphogenesis will answer many pressing questions in development and disease. However, studies of this nature are difficult to address in complex organisms. Drosophila melanogaster is a simple model system for many conserved aspects of muscle development, and from studies in Drosophila embryos, larvae, and adults, we can now describe cellular processes such as myoblast fusion, nuclear positioning, tendon attachment, innervation, and sarcomere formation with a great level of detail.

Despite the large datasets acquired to date, our knowledge is far from complete, and many important questions remain. For example, what counting mechanisms are in place to achieve myofibers of the appropriate size during fusion? How do nuclei retain even spacing as the muscles grow significantly during development, and why are clustered myonuclei consistently smaller than normal $?^{12,40-42,44}$ How do signaling cascades and Integrin activation affect other aspects of myogenesis? What role does nuclear positioning play in the adult musculature? Finally, what other intrinsic and extrinsic factors are involved in regulating these highly reproducible cellular activities, and how are all of these morphogenetic events temporally coordinated?

To answer these, and many other, questions, it will be important to elucidate the finer details of these cellular processes. Advancements in in vivo imaging techniques, exploratory screening approaches, ${ }^{119}$ and the development of other useful protocols in Drosophila ${ }^{67}$ will facilitate more accurate descriptions of both embryonic and adult myogenesis with greater precision than previously attainable. Such studies will answer many of these outstanding questions, drive an era of new inquiry, and shed light on cases of muscle disease.

\section{Acknowledgments}

We apologize to our colleagues for instances when, due to space constrains, we were unable to directly cite their work.

\section{References}

1. Bate M. The embryonic development of larval muscles in Drosophila. Development. 1990; 110:791-804. [PubMed: 2100994]

2. Dobi KC, Schulman VK, Baylies MK. Specification of the somatic musculature in Drosophila melanogaster. WIREs Dev Biol. 201510.1002/wdev.182

3. Crisp S, Evers JF, Fiala A, Bate M. The development of motor coordination in Drosophila embryos. Development. 2008; 135:3707-3717. [PubMed: 18927150] 
4. Demontis F, Perrimon N. Integration of Insulin receptor/Foxo signaling and dMyc activity during muscle growth regulates body size in Drosophila. Development. 2009; 136:983-993. [PubMed: 19211682]

5. Clark KA, Bland JM, Beckerle MC. The Drosophila muscle LIM protein, Mlp84B, cooperates with D-titin to maintain muscle structural integrity. J Cell Sci. 2007; 120:2066-2077. [PubMed: 17535853]

6. Baylies MK, Bate M, Ruiz Gomez M. Myogenesis: a view from Drosophila. Cell. 1998; 93:921927. [PubMed: 9635422]

7. Abmayr SM, Pavlath GK. Myoblast fusion: lessons from flies and mice. Development. 2012; 139:641-656. [PubMed: 22274696]

8. Chen EH. Invasive podosomes and myoblast fusion. Curr Top Membr. 2011; 68:235-258. [PubMed: 21771502]

9. Rochlin K, Yu S, Roy S, Baylies MK. Myoblast fusion: when it takes more to make one. Dev Biol. 2010; 341:66-83. [PubMed: 19932206]

10. Sens KL, Zhang S, Jin P, Duan R, Zhang G, Luo F, Parachini L, Chen EH. An invasive podosomelike structure promotes fusion pore formation during myoblast fusion. J Cell Biol. 2010; 191:1013-1027. [PubMed: 21098115]

11. Duan R, Jin P, Luo F, Zhang G, Anderson N, Chen EH. Group I PAKs function downstream of Rac to promote podosome invasion during myoblast fusion in vivo. J Cell Biol. 2012; 199:169_ 185. [PubMed: 23007650]

12. Metzger T, Gache V, Xu M, Cadot B, Folker ES, Richardson BE, Gomes ER, Baylies MK. MAP and kinesin-dependent nuclear positioning is required for skeletal muscle function. Nature. 2012; 484:120-124. [PubMed: 22425998]

13. Beckett K, Baylies MK. 3D analysis of founder cell and fusion competent myoblast arrangements outlines a new model of myoblast fusion. Dev Biol. 2007; 309:113-125. [PubMed: 17662708]

14. Ruiz-Gomez M, Coutts N, Price A, Taylor MV, Bate M. Drosophila dumbfounded: a myoblast attractant essential for fusion. Cell. 2000; 102:189-198. [PubMed: 10943839]

15. Strunkelnberg M, Bonengel B, Moda LM, Hertenstein A, de Couet HG, Ramos RG, Fischbach KF. rst and its paralogue kirre act redundantly during embryonic muscle development in Drosophila. Development. 2001; 128:4229-4239. [PubMed: 11684659]

16. Bour BA, Chakravarti M, West JM, Abmayr SM. Drosophila SNS, a member of the immunoglobulin superfamily that is essential for myoblast fusion. Genes Dev. 2000; 14:14981511. [PubMed: 10859168]

17. Artero RD, Castanon I, Baylies MK. The immunoglobulin-like protein Hibris functions as a dosedependent regulator of myoblast fusion and is differentially controlled by Ras and Notch signaling. Development. 2001; 128:4251-4264. [PubMed: 11684661]

18. Shelton C, Kocherlakota KS, Zhuang S, Abmayr SM. The immunoglobulin superfamily member Hbs functions redundantly with Sns in interactions between founder and fusion-competent myoblasts. Development. 2009; 136:1159-1168. [PubMed: 19270174]

19. Bothe I, Deng S, Baylies M. PI(4,5)P2 regulates myoblast fusion through Arp2/3 regulator localization at the fusion site. Development. 2014; 141:2289-2301. [PubMed: 24821989]

20. Menon SD, Chia W. Drosophila rolling pebbles: a multidomain protein required for myoblast fusion that recruits D-Titin in response to the myoblast attractant Dumbfounded. Dev Cell. 2001; 1:691-703. [PubMed: 11709189]

21. Chen EH, Olson EN. Antisocial, an intracellular adaptor protein, is required for myoblast fusion in Drosophila. Dev Cell. 2001; 1:705-715. [PubMed: 11709190]

22. Bulchand S, Menon SD, George SE, Chia W. The intracellular domain of Dumbfounded affects myoblast fusion efficiency and interacts with Rolling pebbles and Loner. PLoS One. 2010; 5:e9374. [PubMed: 20186342]

23. Kaipa BR, Shao H, Schafer G, Trinkewitz T, Groth V, Liu J, Beck L, Bogdan S, Abmayr SM, Onel SF. Dock mediates Scar- and WASp-dependent actin polymerization through interaction with cell adhesion molecules in founder cells and fusion-competent myoblasts. J Cell Sci. 2013; 126:360372. [PubMed: 22992459] 
24. Erickson MR, Galletta BJ, Abmayr SM. Drosophila myoblast city encodes a conserved protein that is essential for myoblast fusion, dorsal closure, and cytoskeletal organization. J Cell Biol. 1997; 138:589-603. [PubMed: 9245788]

25. Haralalka S, Shelton C, Cartwright HN, Katzfey E, Janzen E, Abmayr SM. Asymmetric Mbc, active Rac1 and F-actin foci in the fusion-competent myoblasts during myoblast fusion in Drosophila. Development. 2011; 138:1551-1562. [PubMed: 21389053]

26. Chen EH, Pryce BA, Tzeng JA, Gonzalez GA, Olson EN. Control of myoblast fusion by a guanine nucleotide exchange factor, loner, and its effector ARF6. Cell. 2003; 114:751-762. [PubMed: 14505574]

27. Richardson BE, Beckett K, Nowak SJ, Baylies MK. SCAR/WAVE and Arp $2 / 3$ are crucial for cytoskeletal remodeling at the site of myoblast fusion. Development. 2007; 134:4357-4367. [PubMed: 18003739]

28. Massarwa R, Carmon S, Shilo BZ, Schejter ED. WIP/WASp-based actin-polymerization machinery is essential for myoblast fusion in Drosophila. Dev Cell. 2007; 12:557-569. [PubMed: 17419994]

29. Berger S, Schafer G, Kesper DA, Holz A, Eriksson T, Palmer RH, Beck L, Klambt C, RenkawitzPohl R, Onel SF. WASP and SCAR have distinct roles in activating the Arp2/3 complex during myoblast fusion. J Cell Sci. 2008; 121:1303-1313. [PubMed: 18388318]

30. Zhang Y, Featherstone D, Davis W, Rushton E, Broadie K. Drosophila D-titin is required for myoblast fusion and skeletal muscle striation. J Cell Sci. 2000; 113(Pt 17):3103-3115. [PubMed: 10934048]

31. Kim S, Shilagardi K, Zhang S, Hong SN, Sens KL, Bo J, Gonzalez GA, Chen EH. A critical function for the actin cytoskeleton in targeted exocytosis of prefusion vesicles during myoblast fusion. Dev Cell. 2007; 12:571-586. [PubMed: 17419995]

32. Jin P, Duan R, Luo F, Zhang G, Hong SN, Chen EH. Competition between Blown fuse and WASP for WIP binding regulates the dynamics of WASP-dependent actin polymerization in vivo. Dev Cell. 2011; 20:623-638. [PubMed: 21571220]

33. Balagopalan L, Chen MH, Geisbrecht ER, Abmayr SM. The CDM superfamily protein MBC directs myoblast fusion through a mechanism that requires phosphatidylinositol 3,4,5-triphosphate binding but is independent of direct interaction with DCrk. Mol Cell Biol. 2006; 26:9442-9455. [PubMed: 17030600]

34. Geisbrecht ER, Haralalka S, Swanson SK, Florens L, Washburn MP, Abmayr SM. Drosophila ELMO/CED-12 interacts with Myoblast city to direct myoblast fusion and ommatidial organization. Dev Biol. 2008; 314:137-149. [PubMed: 18163987]

35. Gildor B, Massarwa R, Shilo BZ, Schejter ED. The SCAR and WASp nucleation-promoting factors act sequentially to mediate Drosophila myoblast fusion. EMBO Rep. 2009; 10:1043-1050. [PubMed: 19644501]

36. Doberstein SK, Fetter RD, Mehta AT, Goodman CS. Genetic analysis of myoblast fusion: blown fuse is required for progression beyond the prefusion complex. J Cell Biol. 1997; 136:1249-1261. [PubMed: 9087441]

37. Schaub C, Frasch M. Org-1 is required for the diversification of circular visceral muscle founder cells and normal midgut morphogenesis. Dev Biol. 2013; 376:245-259. [PubMed: 23380635]

38. Dohrmann C, Azpiazu N, Frasch M. A new Drosophila homeo box gene is expressed in mesodermal precursor cells of distinct muscles during embryogenesis. Genes Dev. 1990; 4:20982111. [PubMed: 1980118]

39. Knirr S, Frasch M. Molecular integration of inductive and mesoderm-intrinsic inputs governs evenskipped enhancer activity in a subset of pericardial and dorsal muscle progenitors. Dev Biol. 2001; 238:13-26. [PubMed: 11783990]

40. Menon SD, Osman Z, Chenchill K, Chia W. A positive feedback loop between Dumbfounded and Rolling pebbles leads to myotube enlargement in Drosophila. J Cell Biol. 2005; 169:909-920. [PubMed: 15955848]

41. Tixier V, Bataille L, Etard C, Jagla T, Weger M, Daponte JP, Strahle U, Dickmeis T, Jagla K. Glycolysis supports embryonic muscle growth by promoting myoblast fusion. Proc Natl Acad Sci USA. 2013; 110:18982-18987. [PubMed: 24191061] 
42. Folker ES, Schulman VK, Baylies MK. Muscle length and myonuclear position are independently regulated by distinct Dynein pathways. Development. 2012; 139:3827-3837. [PubMed: 22951643]

43. Elhanany-Tamir H, Yu YV, Shnayder M, Jain A, Welte M, Volk T. Organelle positioning in muscles requires cooperation between two KASH proteins and microtubules. J Cell Biol. 2012; 198:833-846. [PubMed: 22927463]

44. Schulman VK, Folker ES, Rosen JN, Baylies MK. Syd/JIP3 and JNK signaling are required for myonuclear positioning and muscle function. PLoS Genet. 2014; 10:e1004880. [PubMed: 25522254]

45. Folker ES, Schulman VK, Baylies MK. Translocating myonuclei have distinct leading and lagging edges that require kinesin and dynein. Development. 2014; 141:355-366. [PubMed: 24335254]

46. Fridolfsson HN, Starr DA. Kinesin-1 and dynein at the nuclear envelope mediate the bidirectional migrations of nuclei. J Cell Biol. 2010; 191:115-128. [PubMed: 20921138]

47. Adames NR, Cooper JA. Microtubule interactions with the cell cortex causing nuclear movements in Saccharomyces cerevisiae. J Cell Biol. 2000; 149:863-874. [PubMed: 10811827]

48. Fant X, Srsen V, Espigat-Georger A, Merdes A. Nuclei of non-muscle cells bind centrosome proteins upon fusion with differentiating myoblasts. PLoS One. 2009; 4:e8303. [PubMed: 20011525]

49. Arimoto M, Koushika SP, Choudhary BC, Li C, Matsumoto K, Hisamoto N. The Caenorhabditis elegans JIP3 protein UNC-16 functions as an adaptor to link kinesin-1 with cytoplasmic dynein. J Neurosci. 2011; 31:2216-2224. [PubMed: 21307258]

50. Roberts AJ, Goodman BS, Reck-Peterson SL. Reconstitution of dynein transport to the microtubule plus end by kinesin. Elife. 2014; 3:e02641. [PubMed: 24916158]

51. Gotta M, Dong Y, Peterson YK, Lanier SM, Ahringer J. Asymmetrically distributed C. elegans homologs of AGS3/PINS control spindle position in the early embryo. Curr Biol. 2003; 13:10291037. [PubMed: 12814548]

52. Mimori-Kiyosue Y, Tsukita S. "Search-and-capture" of microtubules through plus-end-binding proteins (+TIPs). J Biochem. 2003; 134:321-326. [PubMed: 14561716]

53. Fukata M, Watanabe T, Noritake J, Nakagawa M, Yamaga M, Kuroda S, Matsuura Y, Iwamatsu A, Perez F, Kaibuchi K. Rac1 and Cdc42 capture microtubules through IQGAP1 and CLIP-170. Cell. 2002; 109:873-885. [PubMed: 12110184]

54. Kraut R, Campos-Ortega JA. inscuteable, a neural precursor gene of Drosophila, encodes a candidate for a cytoskeleton adaptor protein. Dev Biol. 1996; 174:65-81. [PubMed: 8626022]

55. Verhey KJ, Lizotte DL, Abramson T, Barenboim L, Schnapp BJ, Rapoport TA. Light chaindependent regulation of Kinesin's interaction with microtubules. J Cell Biol. 1998; 143:10531066. [PubMed: 9817761]

56. Horiuchi D, Collins CA, Bhat P, Barkus RV, Diantonio A, Saxton WM. Control of a kinesin-cargo linkage mechanism by JNK pathway kinases. Curr Biol. 2007; 17:1313-1317. [PubMed: 17658258]

57. Fu MM, Holzbaur EL. JIP1 regulates the directionality of APP axonal transport by coordinating kinesin and dynein motors. J Cell Biol. 2013; 202:495-508. [PubMed: 23897889]

58. Malone CJ, Fixsen WD, Horvitz HR, Han M. UNC-84 localizes to the nuclear envelope and is required for nuclear migration and anchoring during C. elegans development. Development. 1999; 126:3171-3181. [PubMed: 10375507]

59. Starr DA, Han M. Role of ANC-1 in tethering nuclei to the actin cytoskeleton. Science. 2002; 298:406-409. [PubMed: 12169658]

60. Crisp M, Liu Q, Roux K, Rattner JB, Shanahan C, Burke B, Stahl PD, Hodzic D. Coupling of the nucleus and cytoplasm: role of the LINC complex. J Cell Biol. 2006; 172:41-53. [PubMed: 16380439]

61. Starr DA. A nuclear-envelope bridge positions nuclei and moves chromosomes. J Cell Sci. 2009; 122:577-586. [PubMed: 19225124]

62. Fridolfsson HN, Ly N, Meyerzon M, Starr DA. UNC-83 coordinates kinesin-1 and dynein activities at the nuclear envelope during nuclear migration. Dev Biol. 2010; 338:237-250. [PubMed: 20005871] 
63. Starr DA, Hermann GJ, Malone CJ, Fixsen W, Priess JR, Horvitz HR, Han M. unc-83 encodes a novel component of the nuclear envelope and is essential for proper nuclear migration. Development. 2001; 128:5039-5050. [PubMed: 11748140]

64. Yu J, Starr DA, Wu X, Parkhurst SM, Zhuang Y, Xu T, Xu R, Han M. The KASH domain protein MSP-300 plays an essential role in nuclear anchoring during Drosophila oogenesis. Dev Biol. 2006; 289:336-345. [PubMed: 16337624]

65. Zhang Q, Ragnauth C, Greener MJ, Shanahan CM, Roberts RG. The nesprins are giant actinbinding proteins, orthologous to Drosophila melanogaster muscle protein MSP-300. Genomics. 2002; 80:473-481. [PubMed: 12408964]

66. Pavlath GK, Rich K, Webster SG, Blau HM. Localization of muscle gene products in nuclear domains. Nature. 1989; 337:570-573. [PubMed: 2915707]

67. Schulman VK, Folker ES, Baylies MK. A method for reversible drug delivery to internal tissues of Drosophila embryos. Fly (Austin). 2013; 7:193-203. [PubMed: 23846179]

68. Hatini V, DiNardo S. Distinct signals generate repeating striped pattern in the embryonic parasegment. Mol Cell. 2001; 7:151-160. [PubMed: 11172720]

69. Becker S, Pasca G, Strumpf D, Min L, Volk T. Reciprocal signaling between Drosophila epidermal muscle attachment cells and their corresponding muscles. Development. 1997; 124:2615-2622. [PubMed: 9217003]

70. Volk T. Singling out Drosophila tendon cells: a dialogue between two distinct cell types. Trends Genet. 1999; 15:448-453. [PubMed: 10529807]

71. Frommer G, Vorbruggen G, Pasca G, Jackle H, Volk T. Epidermal egr-like zinc finger protein of Drosophila participates in myotube guidance. EMBO J. 1996; 15:1642-1649. [PubMed: 8612588]

72. Nabel-Rosen H, Volohonsky G, Reuveny A, Zaidel-Bar R, Volk T. Two isoforms of the Drosophila RNA binding protein, how, act in opposing directions to regulate tendon cell differentiation. Dev Cell. 2002; 2:183-193. [PubMed: 11832244]

73. Kramer SG, Kidd T, Simpson JH, Goodman CS. Switching repulsion to attraction: changing responses to slit during transition in mesoderm migration. Science. 2001; 292:737-740. [PubMed: 11326102]

74. Wayburn B, Volk T. LRT, a tendon-specific leucine-rich repeat protein, promotes muscle-tendon targeting through its interaction with Robo. Development. 2009; 136:3607-3615. [PubMed: 19793885]

75. Yarnitzky T, Min L, Volk T. The Drosophila neuregulin homolog Vein mediates inductive interactions between myotubes and their epidermal attachment cells. Genes Dev. 1997; 11:26912700. [PubMed: 9334331]

76. Liu ZC, Geisbrecht ER. Moleskin is essential for the formation of the myotendinous junction in Drosophila. Dev Biol. 2011; 359:176-189. [PubMed: 21925492]

77. Volohonsky G, Edenfeld G, Klambt C, Volk T. Muscle-dependent maturation of tendon cells is induced by post-transcriptional regulation of stripeA. Development. 2007; 134:347-356. [PubMed: 17166919]

78. Callahan CA, Bonkovsky JL, Scully AL, Thomas JB. Derailed is required for muscle attachment site selection in Drosophila. Development. 1996; 122:2761-2767. [PubMed: 8787750]

79. Swan LE, Wichmann C, Prange U, Schmid A, Schmidt M, Schwarz T, Ponimaskin E, Madeo F, Vorbruggen G, Sigrist SJ. A glutamate receptor-interacting protein homolog organizes muscle guidance in Drosophila. Genes Dev. 2004; 18:223-237. [PubMed: 14729572]

80. Swan LE, Schmidt M, Schwarz T, Ponimaskin E, Prange U, Boeckers T, Thomas U, Sigrist SJ. Complex interaction of Drosophila GRIP PDZ domains and Echinoid during muscle morphogenesis. EMBO J. 2006; 25:3640-3651. [PubMed: 16858411]

81. Schnorrer F, Kalchhauser I, Dickson BJ. The transmembrane protein Kon-tiki couples to Dgrip to mediate myotube targeting in Drosophila. Dev Cell. 2007; 12:751-766. [PubMed: 17488626]

82. Estrada B, Gisselbrecht SS, Michelson AM. The transmembrane protein Perdido interacts with Grip and integrins to mediate myotube projection and attachment in the Drosophila embryo. Development. 2007; 134:4469-4478. [PubMed: 18039972]

83. Brown NH. Cell-cell adhesion via the ECM: integrin genetics in fly and worm. Matrix Biol. 2000; 19:191-201. [PubMed: 10936444] 
84. Gotwals PJ, Fessler LI, Wehrli M, Hynes RO. Drosophila PS1 integrin is a laminin receptor and differs in ligand specificity from PS2. Proc Natl Acad Sci USA. 1994; 91:11447-11451. [PubMed: 7972082]

85. Fogerty FJ, Fessler LI, Bunch TA, Yaron Y, Parker CG, Nelson RE, Brower DL, Gullberg D, Fessler JH. Tiggrin, a novel Drosophila extracellular matrix protein that functions as a ligand for Drosophila $\alpha$ PS2 $\beta$ PS integrins. Development. 1994; 120:1747-1758. [PubMed: 7924982]

86. Subramanian A, Wayburn B, Bunch T, Volk T. Thrombospondin-mediated adhesion is essential for the formation of the myotendinous junction in Drosophila. Development. 2007; 134:12691278. [PubMed: 17314133]

87. Gilsohn E, Volk T. Slowdown promotes muscle integrity by modulating integrin-mediated adhesion at the myotendinous junction. Development. 2010; 137:785-794. [PubMed: 20110313]

88. Calderwood DA. Integrin activation. J Cell Sci. 2004; 117:657-666. [PubMed: 14754902]

89. Kim C, Ye F, Hu X, Ginsberg MH. Talin activates integrins by altering the topology of the $\beta$ transmembrane domain. J Cell Biol. 2012; 197:605-611. [PubMed: 22641344]

90. Bouaouina M, Jani K, Long JY, Czerniecki S, Morse EM, Ellis SJ, Tanentzapf G, Schock F, Calderwood DA. Zasp regulates integrin activation. J Cell Sci. 2012; 125:5647-5657. [PubMed: 22992465]

91. Franco-Cea A, Ellis SJ, Fairchild MJ, Yuan L, Cheung TY, Tanentzapf G. Distinct developmental roles for direct and indirect talin-mediated linkage to actin. Dev Biol. 2010; 345:64-77. [PubMed: 20599891]

92. Ellis SJ, Pines M, Fairchild MJ, Tanentzapf G. In vivo functional analysis reveals specific roles for the integrin-binding sites of talin. J Cell Sci. 2011; 124:1844-1856. [PubMed: 21558413]

93. Charvet B, Ruggiero F, Le Guellec D. The development of the myotendinous junction. A review. Muscles Ligaments Tendons J. 2012; 2:53-63. [PubMed: 23738275]

94. Zervas CG, Psarra E, Williams V, Solomon E, Vakaloglou KM, Brown NH. A central multifunctional role of integrin-linked kinase at muscle attachment sites. J Cell Sci. 2011; 124:1316-1327. [PubMed: 21444757]

95. Jani K, Schock F. Zasp is required for the assembly of functional integrin adhesion sites. J Cell Biol. 2007; 179:1583-1597. [PubMed: 18166658]

96. Pines M, Das R, Ellis SJ, Morin A, Czerniecki S, Yuan L, Klose M, Coombs D, Tanentzapf G. Mechanical force regulates integrin turnover in Drosophila in vivo. Nat Cell Biol. 2012; 14:935943. [PubMed: 22885771]

97. Yuan L, Fairchild MJ, Perkins AD, Tanentzapf G. Analysis of integrin turnover in fly myotendinous junctions. J Cell Sci. 2010; 123:939-946. [PubMed: 20179102]

98. Liu ZC, Odell N, Geisbrecht ER. Drosophila importin-7 functions upstream of the Elmo signaling module to mediate the formation and stability of muscle attachments. J Cell Sci. 2013; 126:52105223. [PubMed: 24046451]

99. Prokop A, Meinertzhagen IA. Development and structure of synaptic contacts in Drosophila. Semin Cell Dev Biol. 2006; 17:20-30. [PubMed: 16384719]

100. Landgraf M, Baylies M, Bate M. Muscle founder cells regulate defasciculation and targeting of motor axons in the Drosophila embryo. Curr Biol. 1999; 9:589-592. [PubMed: 10359699]

101. Prokop A. Organization of the efferent system and structure of neuromuscular junctions in Drosophila. Int Rev Neurobiol. 2006; 75:71-90. [PubMed: 17137924]

102. Johansen J, Halpern ME, Johansen KM, Keshishian H. Stereotypic morphology of glutamatergic synapses on identified muscle cells of Drosophila larvae. J Neurosci. 1989; 9:710-725. [PubMed: 2563766]

103. Atwood HL, Govind CK, Wu CF. Differential ultrastructure of synaptic terminals on ventral longitudinal abdominal muscles in Drosophila larvae. J Neurobiol. 1993; 24:1008-1024. [PubMed: 8409966]

104. Budnik V, Zhong Y, Wu CF. Morphological plasticity of motor axons in Drosophila mutants with altered excitability. J Neurosci. 1990; 10:3754-3768. [PubMed: 1700086]

105. Pennetta G, Hiesinger PR, Fabian-Fine R, Meinertzhagen IA, Bellen HJ. Drosophila VAP-33A directs bouton formation at neuromuscular junctions in a dosage-dependent manner. Neuron. 2002; 35:291-306. [PubMed: 12160747] 
106. Tsai PI, Wang M, Kao HH, Cheng YJ, Lin YJ, Chen RH, Chien CT. Activity-dependent retrograde laminin A signaling regulates synapse growth at Drosophila neuromuscular junctions. Proc Natl Acad Sci USA. 2012; 109:17699-17704. [PubMed: 23054837]

107. McCabe BD, Marques G, Haghighi AP, Fetter RD, Crotty ML, Haerry TE, Goodman CS, O'Connor MB. The BMP homolog Gbb provides a retrograde signal that regulates synaptic growth at the Drosophila neuromuscular junction. Neuron. 2003; 39:241-254. [PubMed: 12873382]

108. Zito K, Parnas D, Fetter RD, Isacoff EY, Goodman CS. Watching a synapse grow: noninvasive confocal imaging of synaptic growth in Drosophila. Neuron. 1999; 22:719-729. [PubMed: 10230792]

109. Qin G, Schwarz T, Kittel RJ, Schmid A, Rasse TM, Kappei D, Ponimaskin E, Heckmann M, Sigrist SJ. Four different subunits are essential for expressing the synaptic glutamate receptor at neuromuscular junctions of Drosophila. J Neurosci. 2005; 25:3209-3218. [PubMed: 15788778]

110. Morimoto T, Nobechi M, Komatsu A, Miyakawa H, Nose A. Subunit-specific and homeostatic regulation of glutamate receptor localization by CaMKII in Drosophila neuromuscular junctions. Neuroscience. 2010; 165:1284-1292. [PubMed: 19961909]

111. Rhee D, Sanger JM, Sanger JW. The premyofibril: evidence for its role in myofibrillogenesis. Cell Motil Cytoskeleton. 1994; 28:1-24. [PubMed: 8044846]

112. Holtzer H, Hijikata T, Lin ZX, Zhang ZQ, Holtzer S, Protasi F, Franzini-Armstrong C, Sweeney HL. Independent assembly of 1.6 microns long bipolar MHC filaments and I-Z-I bodies. Cell Struct Funct. 1997; 22:83-93. [PubMed: 9113394]

113. Rui Y, Bai J, Perrimon N. Sarcomere formation occurs by the assembly of multiple latent protein complexes. PLoS Genet. 2010; 6:e1001208. [PubMed: 21124995]

114. Fyrberg E, Kelly M, Ball E, Fyrberg C, Reedy MC. Molecular genetics of Drosophila $a$-actinin: mutant alleles disrupt Z disc integrity and muscle insertions. J Cell Biol. 1990; 110:1999-2011. [PubMed: 2112549]

115. Obermann WM, Gautel M, Weber K, Furst DO. Molecular structure of the sarcomeric M band: mapping of titin and myosin binding domains in myomesin and the identification of a potential regulatory phosphorylation site in myomesin. EMBO J. 1997; 16:211-220. [PubMed: 9029142]

116. Bagnato P, Barone V, Giacomello E, Rossi D, Sorrentino V. Binding of an ankyrin-1 isoform to obscurin suggests a molecular link between the sarcoplasmic reticulum and myofibrils in striated muscles. J Cell Biol. 2003; 160:245-253. [PubMed: 12527750]

117. Gregorio CC, Trombitas K, Centner T, Kolmerer B, Stier G, Kunke K, Suzuki K, Obermayr F, Herrmann B, Granzier H, et al. The NH2 terminus of titin spans the Z-disc: its interaction with a novel 19-kD ligand (T-cap) is required for sarcomeric integrity. J Cell Biol. 1998; 143:10131027. [PubMed: 9817758]

118. Haas JN. Cytoplasmic growth in the muscle fibers of larvae of Drosophila melanogaster. Growth. 1950; 14:277-294. [PubMed: 14823419]

119. Schnorrer F, Schonbauer C, Langer CC, Dietzl G, Novatchkova M, Schernhuber K, Fellner M, Azaryan A, Radolf M, Stark A, et al. Systematic genetic analysis of muscle morphogenesis and function in Drosophila. Nature. 2010; 464:287-291. [PubMed: 20220848]

120. Dickinson M. Insect flight. Curr Biol. 2006; 16:R309-R314. [PubMed: 16682333]

121. Fernandes J, Bate M, Vijayraghavan K. Development of the indirect flight muscles of Drosophila. Development. 1991; 113:67-77. [PubMed: 1765009]

122. Roy S, VijayRaghavan K. Muscle pattern diversification in Drosophila: the story of imaginal myogenesis. Bioessays. 1999; 21:486-498. [PubMed: 10402955]

123. Sudarsan V, Anant S, Guptan P, VijayRaghavan K, Skaer H. Myoblast diversification and ectodermal signaling in Drosophila. Dev Cell. 2001; 1:829-839. [PubMed: 11740944]

124. Dutta D, Anant S, Ruiz-Gomez M, Bate M, VijayRaghavan K. Founder myoblasts and fibre number during adult myogenesis in Drosophila. Development. 2004; 131:3761-3772. [PubMed: 15262890]

125. Bate M, Rushton E, Currie DA. Cells with persistent twist expression are the embryonic precursors of adult muscles in Drosophila. Development. 1991; 113:79-89. [PubMed: 1765010] 
126. Dutta D, Shaw S, Maqbool T, Pandya H, Vijayraghavan K. Drosophila Heartless acts with Heartbroken/Dof in muscle founder differentiation. PLoS Biol. 2005; 3:e337. [PubMed: 16207075]

127. Rivlin PK, Schneiderman AM, Booker R. Imaginal pioneers prefigure the formation of adult thoracic muscles in Drosophila melanogaster. Dev Biol. 2000; 222:450-459. [PubMed: 10837132]

128. Roy S, VijayRaghavan K. Patterning muscles using organizers: larval muscle templates and adult myoblasts actively interact to pattern the dorsal longitudinal flight muscles of Drosophila. J Cell Biol. 1998; 141:1135-1145. [PubMed: 9606206]

129. Mukherjee P, Gildor B, Shilo BZ, VijayRaghavan K, Schejter ED. The actin nucleator WASp is required for myoblast fusion during adult Drosophila myogenesis. Development. 2011; 138:2347-2357. [PubMed: 21558381]

130. Gildor B, Schejter ED, Shilo BZ. Bidirectional Notch activation represses fusion competence in swarming adult Drosophila myoblasts. Development. 2012; 139:4040-4050. [PubMed: 23048185]

131. Fernandes JJ, Celniker SE, VijayRaghavan K. Development of the indirect flight muscle attachment sites in Drosophila: role of the PS integrins and the stripe gene. Dev Biol. 1996; 176:166-184. [PubMed: 8660859]

132. Edgecomb RS, Ghetti C, Schneiderman AM. Bendless alters thoracic musculature in Drosophila. J Neurogenet. 1993; 8:201-219. [PubMed: 8320599]

133. Reedy MC, Beall C. Ultrastructure of developing flight muscle in Drosophila. II. Formation of the myotendon junction. Dev Biol. 1993; 160:466-479. [PubMed: 8253278]

134. Costello WJ, Wyman RJ. Development of an indirect flight muscle in a muscle-specific mutant of Drosophila melanogaster. Dev Biol. 1986; 118:247-258. [PubMed: 3095162]

135. Deak II. Mutations of Drosophila melanogaster that affect muscles. J Embryol Exp Morphol. 1977; 40:35-63. [PubMed: 410901]

136. Currie DA, Bate M. The development of adult abdominal muscles in Drosophila: myoblasts express twist and are associated with nerves. Development. 1991; 113:91-102. [PubMed: 1765011]

137. Currie DA, Bate M. Innervation is essential for the development and differentiation of a sexspecific adult muscle in Drosophila melanogaster. Development. 1995; 121:2549-2557. [PubMed: 7671818]

138. Lawrence PA, Johnston P. The muscle pattern of a segment of Drosophila may be determined by neurons and not by contributing myoblasts. Cell. 1986; 45:505-513. [PubMed: 3085954]

139. Fernandes J, Keshishian H. Patterning the dorsal longitudinal flight muscles (DLM) of Drosophila: insights from the ablation of larval scaffolds. Development. 1996; 122:3755-3763. [PubMed: 9012497]

140. Fernandes JJ, Keshishian H. Nerve-muscle interactions during flight muscle development in Drosophila. Development. 1998; 125:1769-1779. [PubMed: 9521914]

141. Fernandes I, Schock F. The nebulin repeat protein Lasp regulates I-band architecture and filament spacing in myofibrils. J Cell Biol. 2014; 206:559-572. [PubMed: 25113030]

142. Weitkunat M, Kaya-Copur A, Grill SW, Schnorrer F. Tension and force-resistant attachment are essential for myofibrillogenesis in Drosophila flight muscle. Curr Biol. 2014; 24:705-716. [PubMed: 24631244]

143. Spletter ML, Schnorrer F. Transcriptional regulation and alternative splicing cooperate in muscle fiber-type specification in flies and mammals. Exp Cell Res. 2014; 321:90-98. [PubMed: 24145055]

144. Schonbauer C, Distler J, Jahrling N, Radolf M, Dodt HU, Frasch M, Schnorrer F. Spalt mediates an evolutionarily conserved switch to fibrillar muscle fate in insects. Nature. 2011; 479:406-409. [PubMed: 22094701]

145. Schweitzer R, Zelzer E, Volk T. Connecting muscles to tendons: tendons and musculoskeletal development in flies and vertebrates. Development. 2010; 137:2807-2817. [PubMed: 20699295] 


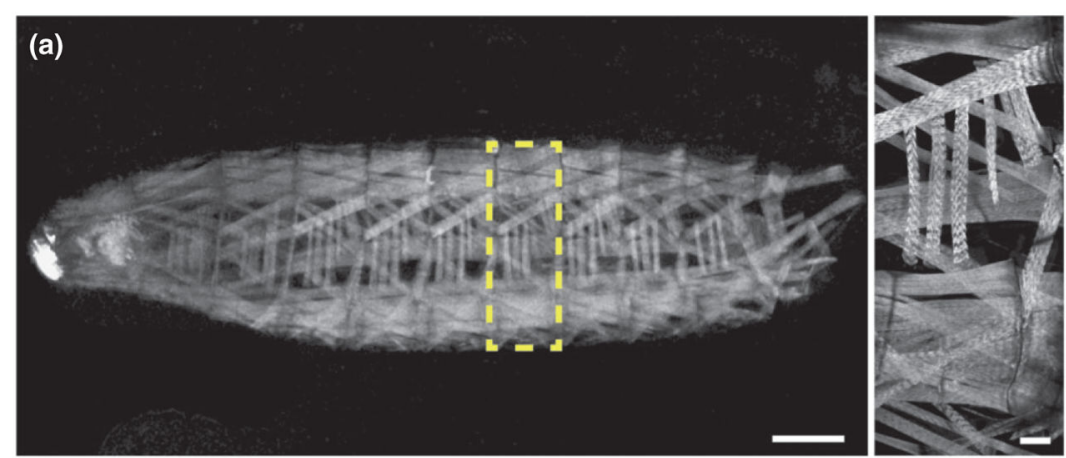

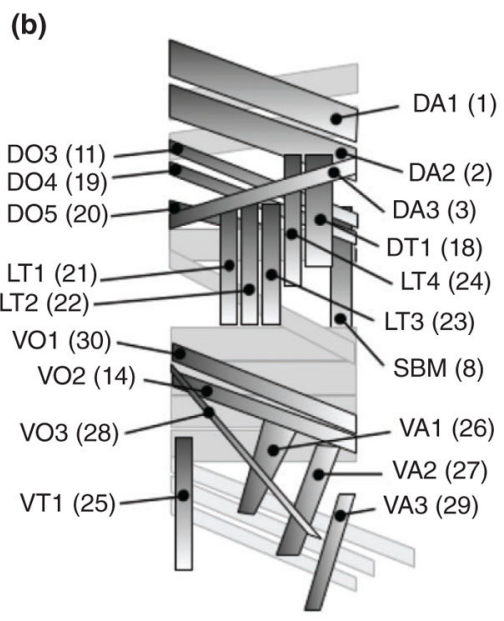

External view (c)

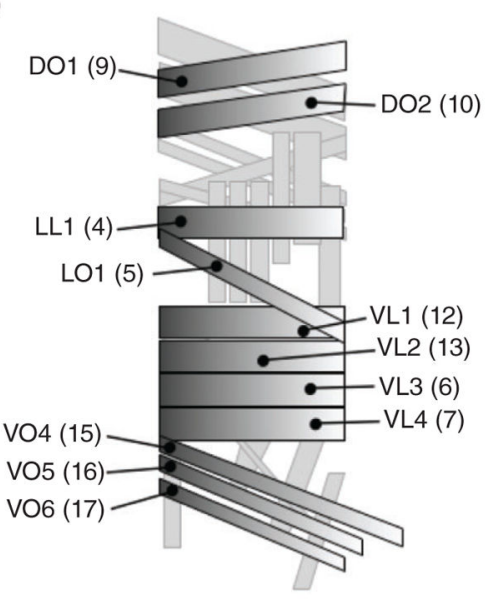

Internal view

FIGURE 1.

Drosophila larval body wall muscles. (a) Stage L3 Drosophila larva expressing tropomyosin (TM1)-GFP (grayscale). Anterior, left; Dorsal, up. (Left) Whole larva. Yellow box highlights one hemisegment shown at higher magnification to the right. Scale bar, $100 \mu \mathrm{m}$. (Right) One hemisegment. Scale bar, $25 \mu \mathrm{m}$. (b) Schematic diagram of the 30 distinct muscles within each hemisegment. External view, as seen in A. (c) Internal view, internalmost and external-most muscles in B reversed. Muscle identities are as follows: Muscle position (D, dorsal; V, ventral; L, lateral) followed by orientation (A, acute; L, longitudinal; $\mathrm{O}$, oblique; T, transverse); SBM, segment border muscle. Former muscle numbering system shown in parentheses. 


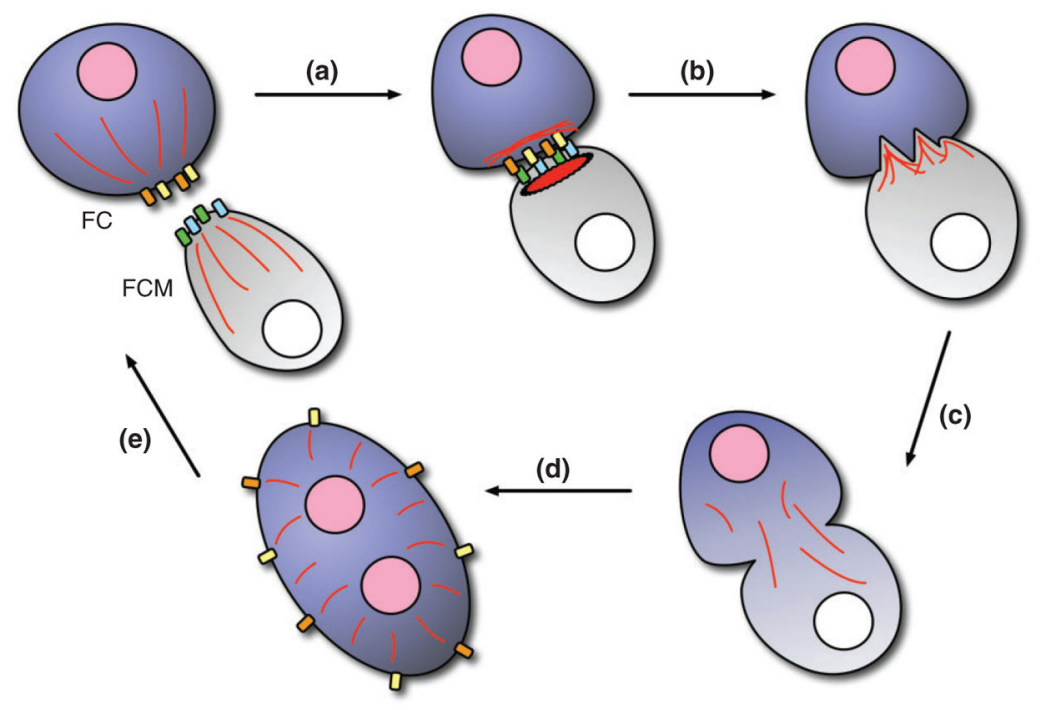

FIGURE 2.

Overview of myoblast fusion. (a) A founder cell (FC, purple) and a fusion-competent myoblast (FCM, gray) recognize and adhere to each other via cell type-specific Immunoglobin (Ig) domain-containing transmembrane proteins (yellow/orange, blue/green). Recognition between FCs and FCMs is thought to promote clustering of Ig domaincontaining proteins at the cell surface to facilitate adhesion. (b) Cytoskeletal rearrangements (actin, red) in both cells lead to pore formation in the cell membranes. (c) Cytoplasmic mixing occurs upon fusion. (d) The previously naïve (white) nucleus of the FCM adopts the transcriptional profile of the FC nucleus (pink), aiding in the development of a particular muscle fate. (e) The FC/growing myofiber recycles Ig domain-containing transmembrane proteins to the cell surface to prepare for additional rounds of myoblast fusion. 


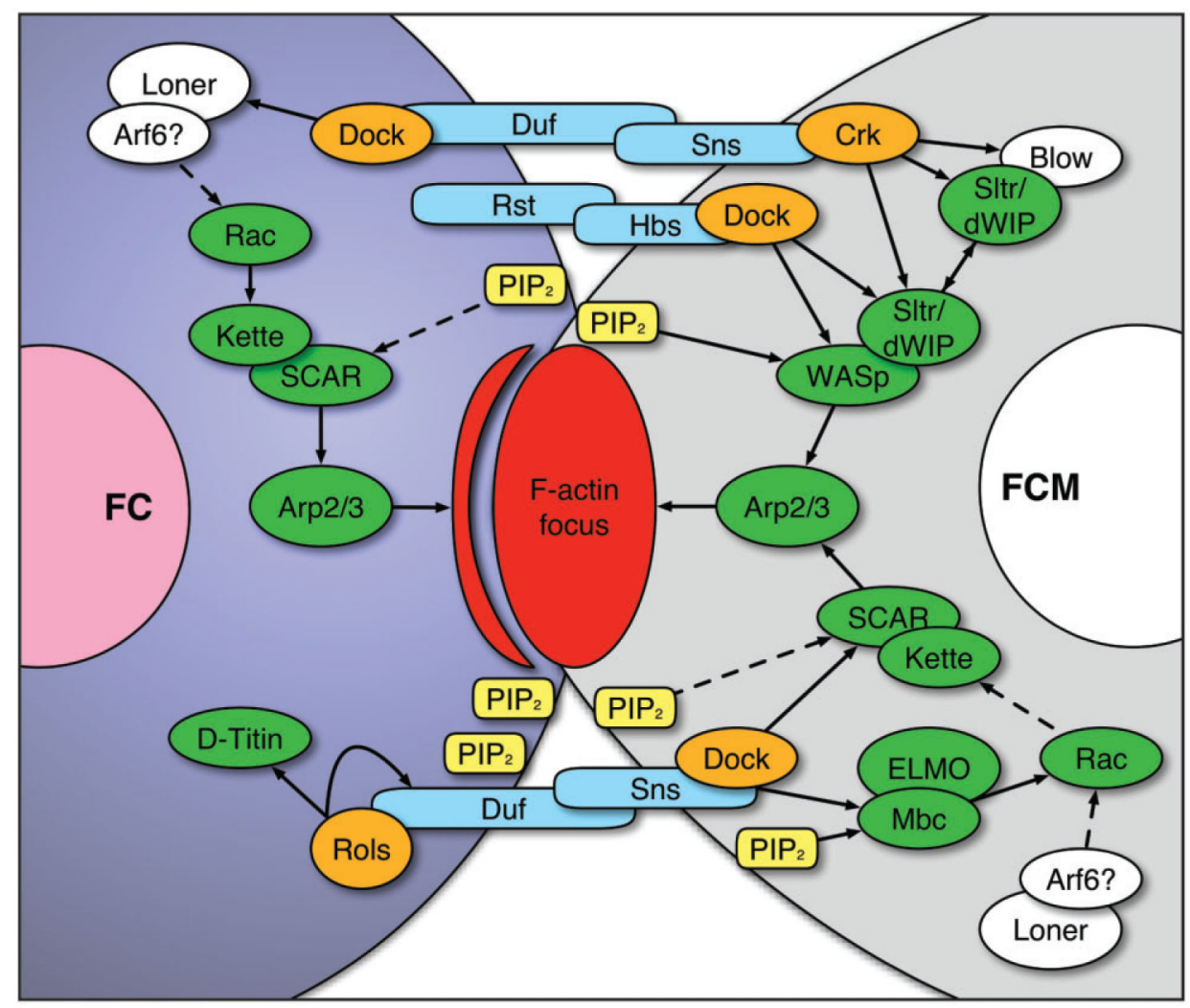

FIGURE 3.

Intracellular signaling cascades necessary for cytoskeletal remodeling and myoblast fusion. The extracellular domains of cell type-specific Immunoglobin (Ig) domain-containing proteins (blue) on both the founder cell (FC, left) and the fusion-competent myoblast (FCM, right) interact to adhere to each other. $\mathrm{PI}(4,5) \mathrm{P} 2\left(\mathrm{PIP}_{2}\right.$, yellow) becomes enriched in the membranes at the contact site, and via adaptor proteins (orange), the intracellular domains of the Ig domain-containing proteins induce downstream signaling events (green) that lead to activation of the Arp2/3 complex, which mediates branched actin polymerization. These activities facilitate the formation of a dense actin focus (red) in the FCM and a thin sheath of actin (red stripe) in the FC that apposes the focus. Continued actin remodeling, mediated by proteins required to dissolve the actin focus (white), induces actin filaments to protrude into the FC, leading to pore formation in the cell membranes and fusion of the two cells. Duf, Dumbfounded; Rst, Roughest; Sns, Sticks-n-stones; Hbs, Hibris; Crk, Crack; Dock, Dreadlock; Rols, Rolling pebbles; Blow, Blown fuse; Sltr/dWIP, Solitary/Drosophila WASp-interacting protein; WASp, Wiskott-Aldrich Syndrome protein; Mbc, Myoblast city. Not shown is Pak1 and Pak3 activity downstream of Rac, which regulates further actin rearrangements for invasive podosome formation. 
(a)

(b)

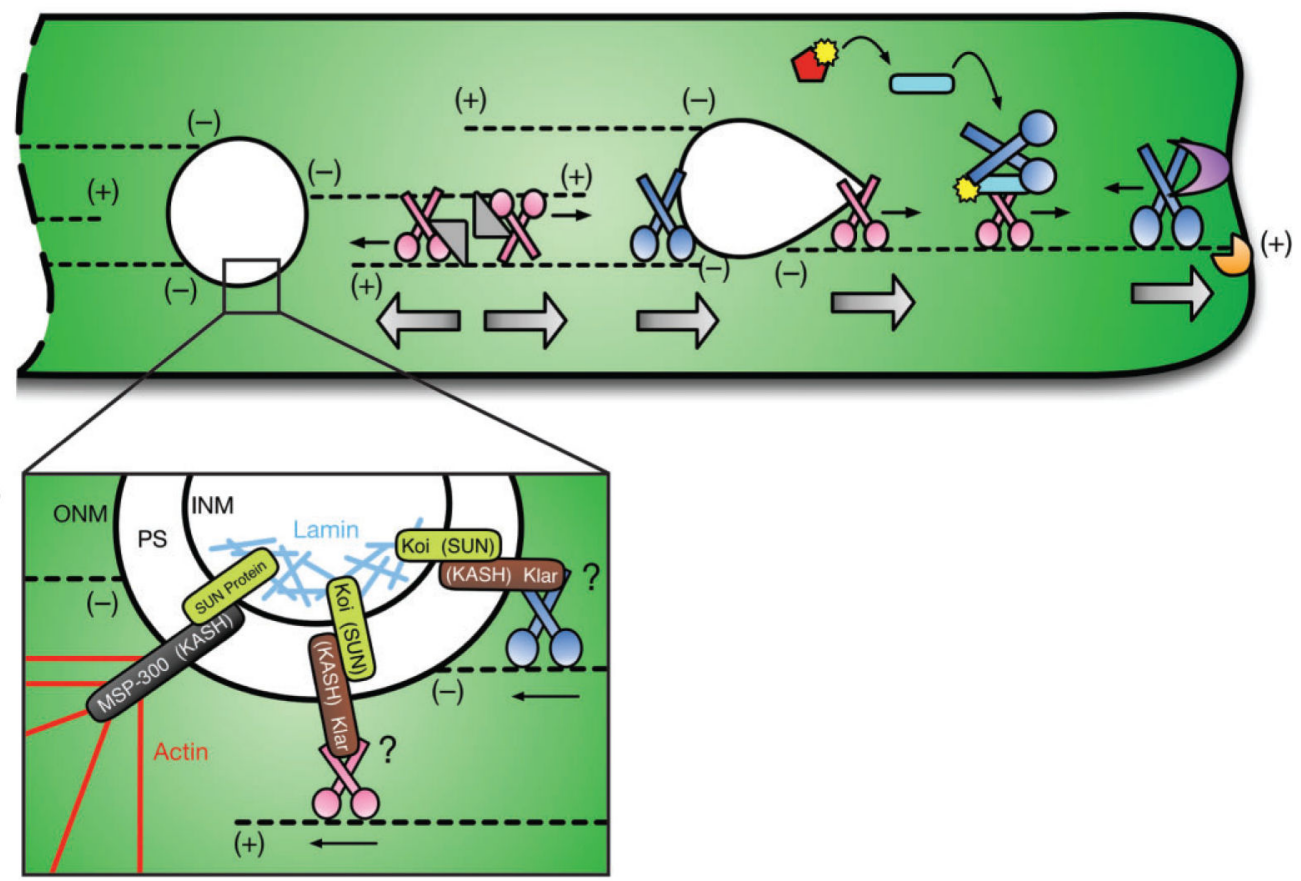

FIGURE 4.

Overview of myonuclear positioning. (a) In multinucleated myofibers (green), microtubules (black dotted lines) originate at the nuclear periphery (minus (-) ends) and extend outwards (plus (+) ends). Following myoblast fusion, Kinesin (pink) and Ensconsin (Ens, gray triangle) work together to separate adjacent myonuclei (white) by crosslinking microtubules and sliding them past one another. Kinesin forces also extend the leading edge of moving nuclei (white teardrop) while Dynein activity (dark blue) at the rear of the nucleus allows forward motion to complete a translocation step. Activation of the JNK signaling pathway (red, curved black arrows) phosphorylates (yellow) Sunday Driver (Syd, light blue rod), which facilitates Kinesin-dependent relocation of Dynein to the cell periphery. Rapsynoid (Raps, purple) anchors Dynein to the cell cortex, and cortical Dynein activity pulls microtubules and the attached nuclei closer to the muscle end. During these movements, CLIP-190 (orange) is necessary to support the integrity of the microtubule network by ensuring proper contact with the cell cortex. Straight thin black arrows denote the direction of motor protein activity. Large silver arrows highlight the direction of net force exerted on nuclei. (b) Within the perinuclear space (PS) of the nuclear envelope, SUN proteins (light green) in the inner nuclear membrane (INM) interact with KASH proteins (black, brown) in the outer nuclear membrane (ONM) to link the nucleoskeleton (light blue, Lamin) and the cytoskeleton (red, Actin) to anchor nuclei in place. It has also been proposed that SUN and KASH proteins may directly link the nucleus to the motor proteins, Kinesin (pink) and Dynein (blue). 


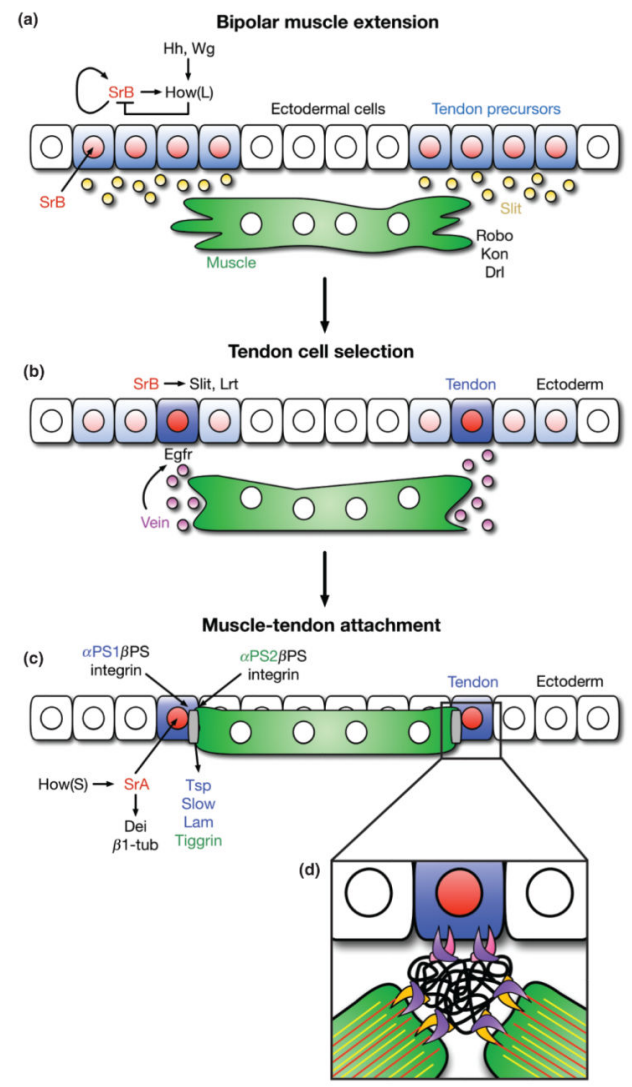

\section{FIGURE 5.}

Overview of muscle attachment to tendon cells. (a) Fields of tendon precursor cells are specified by Wingless $(\mathrm{Wg})$ and Hedgehog $(\mathrm{Hh})$ signaling gradients in the overlying ectoderm. All equally competent cells (blue) express StripeB ( $\mathrm{SrB}$, red), which autoregulates its own expression as well as the expression of $\mathrm{How}(\mathrm{L})$, a $\mathrm{SrB}$ inhibitor. A balance of $\mathrm{SrB}$ and $\operatorname{How}(\mathrm{L})$ maintains a low level of $\mathrm{SrB}$ expression in all tendon precursor cells, preventing further differentiation. Tendon precursor cells secret Slit (orange), a chemoattractant for extending myofibers. The transmembrane receptor, Roundabout (Robo), on the surface of the myofiber responds to Slit secretion, and the myofiber extends filopodia toward the field of tendon precursor cells. (b) Upon Robo activation, the myofiber secretes Vein (purple), an Egfr ligand that binds to DERs on one tendon precursor cell. Interactions between Robo and Leucine-rich tendon-specific protein (Lrt), a transmembrane receptor expressed by the tendon precursor cell, solidify the attachment to the extending muscle end. (c) DER-mediated Ras signaling occurs in only the selected tendon precursor cell bound to the muscle. This leads to dedifferentiation of neighboring cells (faded blue) and upregulation of Stripe A (SrA) and How(S) in the selected cell. How(S) stabilizes SrA transcripts, and SrA mediates terminal differentiation into a mature tendon cell (dark blue). A preliminary attachment between the tendon cell and the myofiber mediates the secretion of extracellular matrix proteins from both cell types (Thrombospondin (Tsp), Laminin (Lam), and Tiggrin, colored respectively), which contribute to the formation of the myotendinous junction (MTJ, gray). (d) Both cells express $\beta \mathrm{PS}$ (purple) Integrin, while the tendon cell specifically expresses $a \mathrm{PS} 1$ (pink) and the myofiber expresses $a \mathrm{PS} 2$ (orange) Integrin adhesion 
molecules. These transmembrane proteins heterodimerize on the surfaces of their respective cell types and bind to ECM proteins (black). $\alpha$ - $\beta$ Integrin dimers also bind to the intracellular cytoskeletons of each cell type, forming stable connections between the tendon cell, the MTJ, and the myofiber, which can withstand the contractive forces of the mature muscle. Kon, Kon-tiki; Drl, Derailed (additional transmembrane proteins for targeting muscles to tendon cells). Dei, Delilah; $\beta 1$-tub, $\beta 1$-tubulin (markers of terminal tendon cell differentiation). Slow, Slowdown (secreted by tendon cell to ensure proper temporal regulation of MTJ formation). (Modified with permission from Ref 145. Copyright 2010 Company of Biologists) 
(a)
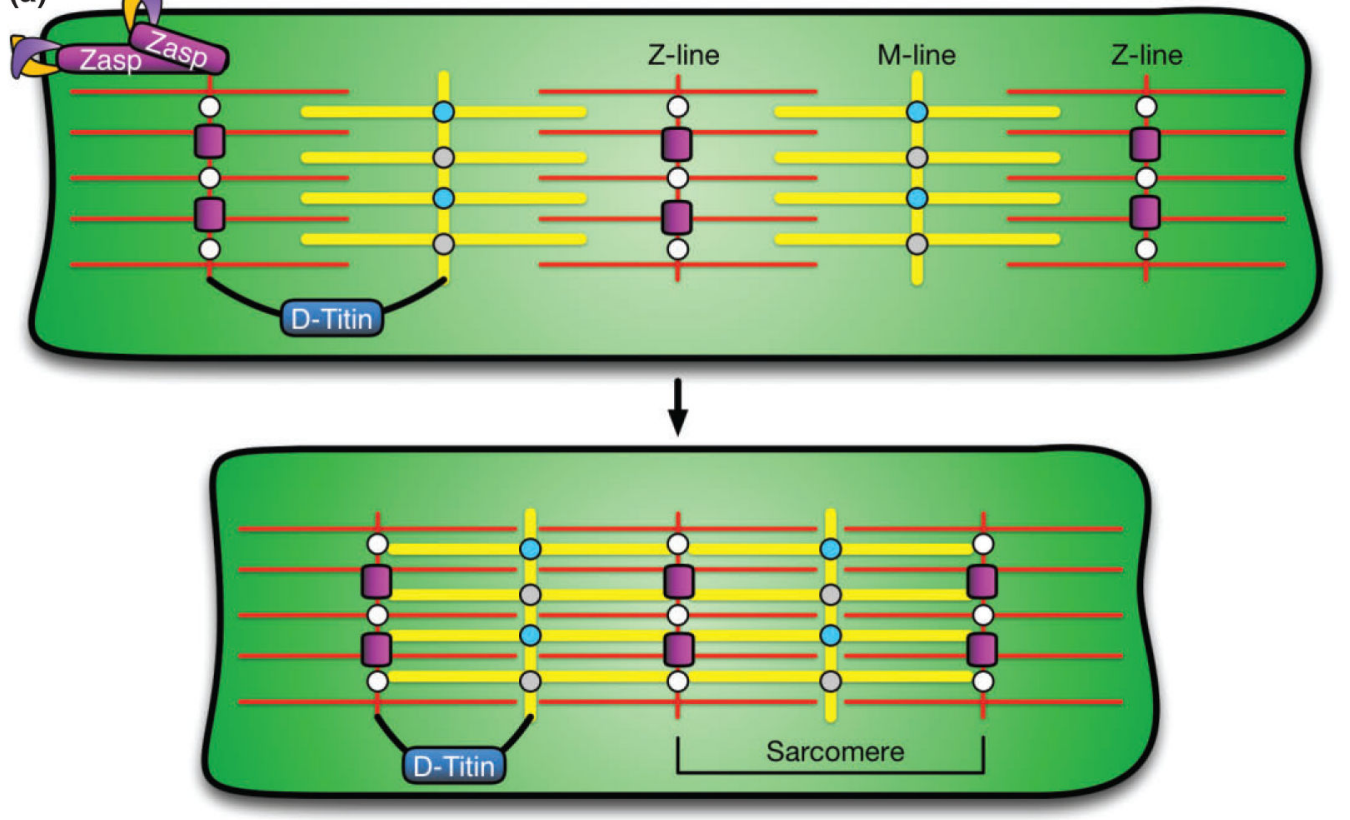

(b)

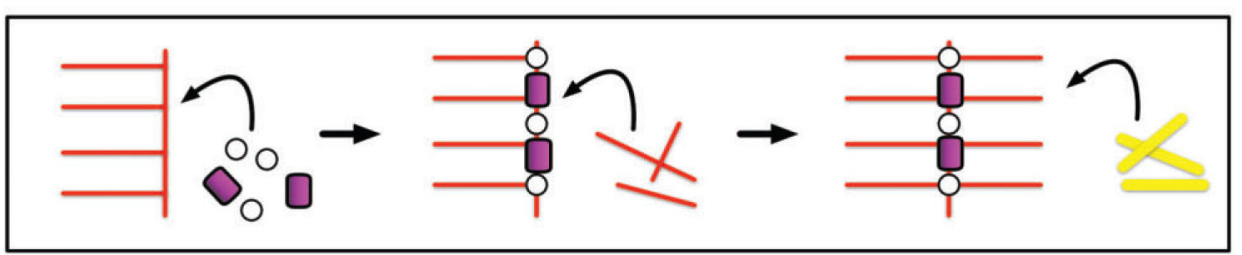

(c)

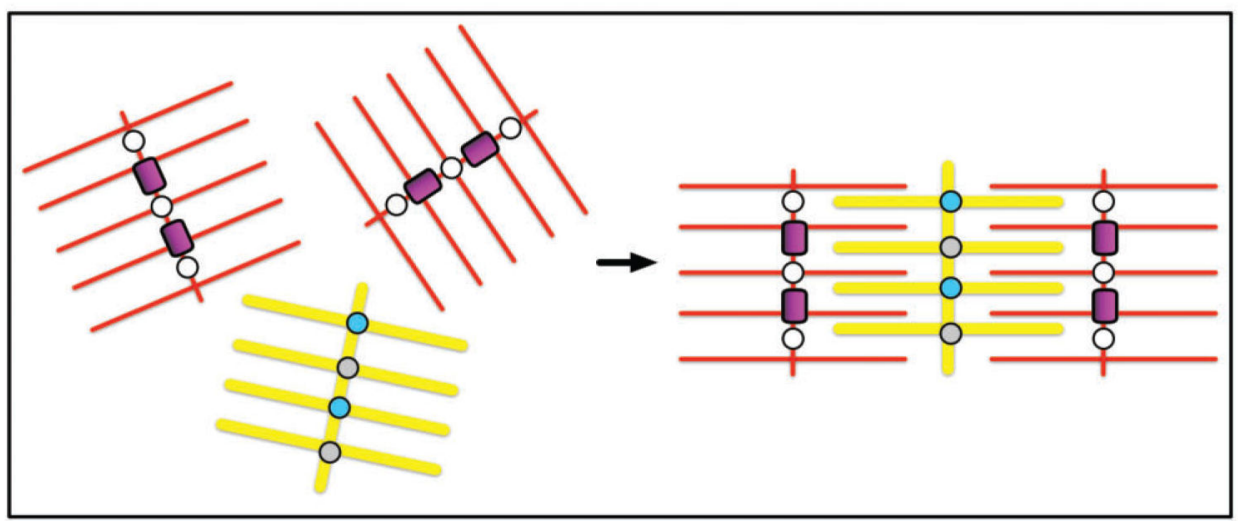

FIGURE 6.

Diagram of sarcomere structure and formation. (a) Sarcomeres are composed of intercalated actin thin filaments (red) and myosin thick filaments (yellow) that slide past one another to compress the muscle in the longitudinal direction. Myosin filaments are held together by Myomesin (light blue) and Obscurrin (gray) at a structure known as the M-line. Actin filaments are held together by $\alpha$-actinin (white) and Zasp (magenta) at a structure called the Z-line (or Z-disk). The distance between two Z-lines constitutes one sarcomere. Zasp in the Z-line also connects sarcomeres to the cell membrane by interacting with Integrin adhesion complexes (purple/orange). D-Titin (dark blue, black) is a component of both of both the Zline and the M-line, connecting the two structures to modulate sarcomere length during 
contraction. (b) One proposed model of sarcomerogenesis in which individual components are sequentially added. ${ }^{111}$ (c) Alternative model of sarcomerogenesis in which lattices of actin or myosin filaments are formed separately and subsequently intercalated together. ${ }^{112,113}$ 
(a)

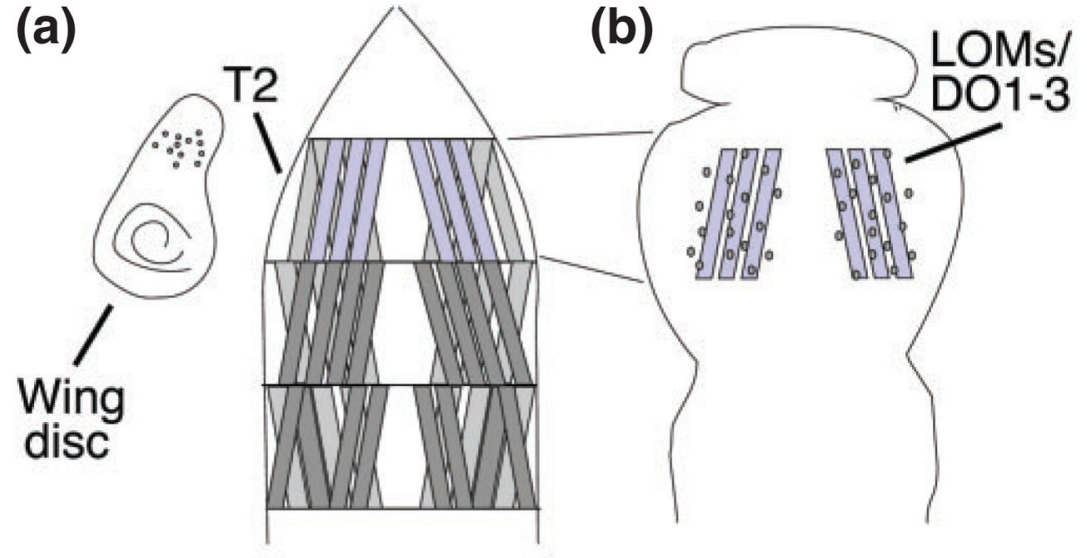

(c)

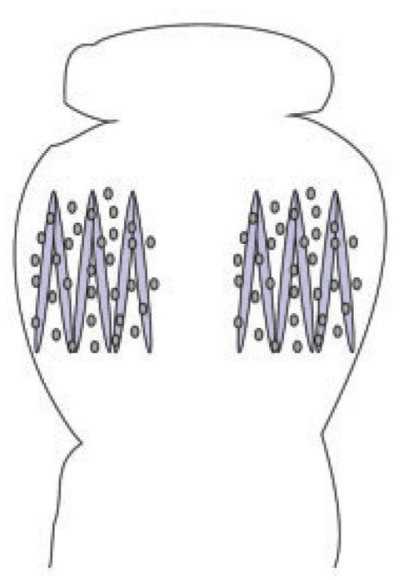

(d)

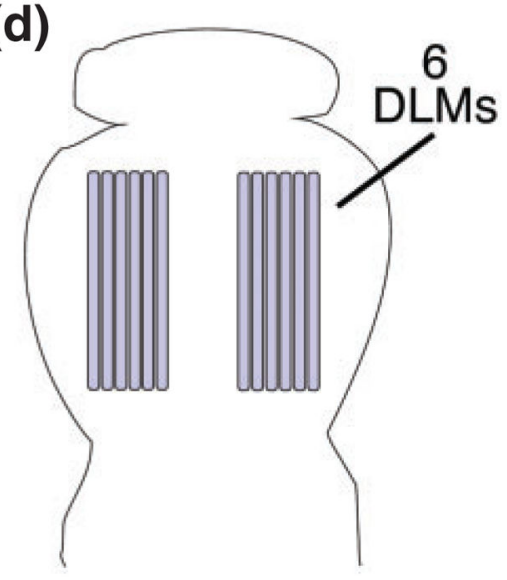

FIGURE 7.

Myoblast fusion in the adult Drosophila musculature. (a) Three muscles (blue) in the second thoracic hemisegments (T2) persist into metamorphosis and serve as scaffolds for the development of the dorsal longitudinal muscles (DLMs). Myoblasts are associated with the wing imaginal disk. (0 $\mathrm{h}$ after puparium formation, APF) (b) A wave of histolysis destroys the other larval muscles early in pupal development. The persistent muscles are surrounded by myoblasts (6- $8 \mathrm{~h}$ APF). (c) The myoblasts begin to fuse and the larval muscles split to give rise to the six DLM fibers (14-18 h APF). (d) The six DLMs grow to fill the thoracic space and are one-third their adult size at $36 \mathrm{~h} \mathrm{APF}$. (Reprinted with permission from Ref 139. Copyright 1996 Company of Biologists) 